\title{
Influence of the Tropics on the Southern Annular Mode
}

\author{
QINGHUA DING AND ERIC J. STEIG \\ Department of Earth and Space Sciences and Quaternary Research Center, University of Washington, Seattle, Washington \\ DAVID S. BATTISTI AND JOHN M. WALLACE \\ Department of Atmospheric Sciences, University of Washington, Seattle, Washington
}

(Manuscript received 15 September 2011, in final form 5 April 2012)

\begin{abstract}
Perturbations in the southern annular mode (SAM) are shown to be significantly correlated with SST anomalies in the central tropical Pacific during austral winter and SST anomalies in the eastern tropical Pacific during austral summer. The SAM signature in the Pacific sector resembles a tropically forced Rossby wave train, the so-called Pacific-South American pattern, while the signature in the Indian Ocean sector is a zonally elongated meridional dipole. Thus, the SAM contains strong zonally asymmetric variability and tends to behave differently in the Eastern and Western Hemispheres, with internal dynamics prevailing in the Indian Ocean sector and the forced response to tropical SST anomalies exerting a strong influence in the Pacific sector. The tropically forced component of the SAM in the Pacific sector is related to a geographically fixed active Rossby wave source to the east of Australia within the core of the subtropical jet. In addition to the well-documented positive trend in summer, the SAM also exhibits a negative wintertime trend since 1979, characterized by prominent geopotential height increases over the high latitudes. In both seasons, SAM trends are closely linked to long-term trends in tropical Pacific SST that are independent of the canonical eastern Pacific ENSO variability. Although the SAM is an intrinsic pattern of high-latitude variability, the SAM index reflects the superposition of both high-latitude and tropically forced variability.
\end{abstract}

\section{Introduction}

The variability of Southern Hemisphere ( $\mathrm{SH}$ ) atmospheric circulation is dominated by an approximately zonally symmetric pattern, referred to as the southern annular mode (SAM), characterized by a dipole in the zonal wind strength with opposing centers of action near $40^{\circ}$ and $65^{\circ} \mathrm{S}$ and an equivalent barotropic structure in the vertical (Kidson 1988; Karoly 1990; Shiotani 1990; Hartmann and Lo 1998; Feldstein and Lee 1998; Limpasuvan and Hartmann 2000; Thompson and Wallace 2000; Lorenz and Hartmann 2001; Vallis et al. 2004; Rashid and Simmonds 2004). The SAM, which accounts for $20 \%-$ $30 \%$ of the total monthly sea level pressure (SLP) or geopotential height variability south of $20^{\circ} \mathrm{S}$ (Thompson and Wallace 2000), was previously referred to as the "high-latitude mode" (e.g., Karoly 1990; Kidson 1999)

Corresponding author address: Qinghua Ding, Department of Earth and Space Sciences, and Quaternary Research Center, University of Washington, Seattle, WA 98195.

E-mail: qinghua@uw.edu and the "Antarctic Oscillation (AAO)" (Thompson and Wallace 2000).

The storm track in the SH exhibits substantial northsouth migration in association with variations of the SAM (Kidson and Sinclair 1995; Codron 2005), which have been related to variations in sea surface temperature (Mo 2000; Hall and Visbeck 2002; Screen et al. 2009), ocean circulation (e.g., Hall and Visbeck 2002; Sen Gupta and England 2006), sea ice (Lefebvre et al. 2004; Stammerjohn et al. 2008), biological productivity (Lovenduski and Gruber 2005), the carbon cycle (Butler et al. 2007; Lovenduski et al. 2007), and midlatitude precipitation (e.g., Silvestri and Vera 2003; Gillett et al. 2006; Hendon et al. 2007). These impacts of the SAM on the SH climate show strong seasonality, indicating that SAM variability is sensitive to the seasonal characteristics of the basic state (Ciasto and Thompson 2008; Kidston et al. 2009; Sallée et al. 2010).

Observational and modeling studies suggest that the SAM is maintained by a positive feedback of the highfrequency transient eddies in the storm track upon the zonally averaged zonal flow (e.g., Karoly 1990; Robinson 
1991; Hartmann and Lo 1998; Limpasuvan and Hartmann 2000; Lorenz and Hartmann 2001; Codron 2005). It is thus widely accepted that the SAM owes its existence to internal atmospheric dynamics, although interactions with the surface ocean and stratosphere may contribute to its variance (Watterson 2001; Thompson et al. 2005; Sen Gupta and England 2007). Long-term variability in the SAM has generally been attributed to the direct impact of radiative forcing. In particular, in recent decades, the SAM has exhibited a trend toward positive polarity during summer, manifested as a strengthening of the circumpolar westerlies along $60^{\circ} \mathrm{S}$, which has been attributed both to stratospheric ozone depletion and to increased greenhouse gas concentrations (Thompson and Solomon 2002; Gillett and Thompson 2003; Marshall et al. 2004; Shindell and Schmidt 2004; Arblaster and Meehl 2006; Miller et al. 2006).

In contrast to the perspective in which the SAM is viewed primarily as an intrinsic feature of high-latitude atmospheric dynamics, a few studies have suggested that tropical sea surface temperature (SST) forcing has a significant impact on the SAM. For example, Grassi et al. (2005) suggested that the tropical SST in austral summer has a significant impact on the SAM by altering the propagation of planetary waves, which in turn affect the midlatitude jet and hence the SAM. L'Heureux and Thompson (2006) found that SAM and El Niño-Southern Oscillation (ENSO)-related circulation anomalies exhibit common features during austral summer [DecemberFebruary (DJF)] and that about $25 \%$ of variance of the SAM index is related to ENSO variations. Similarly, Fogt and Bromwich (2006) found that the occurrence of a positive SAM index is more likely during strong La Niña years. The most recent example of the concurrence of ENSO- and SAM-related anomalies was in 2010. Both widely used SAM indices [the NOAA AAO index and the Marshall (2003) SAM index] show an extreme positive phase of the SAM, characterized by negative height anomalies over Antarctica and positive anomalies in midlatitudes, in the 2010 winter [JuneAugust (JJA)] and spring [September-Novemeber (SON)] (Blunden et al. 2011). Simultaneous with the extreme in the SAM index, there was a significant La Niña event in the tropics (Kim et al. 2011). Although ENSO and the SAM tend to be viewed as independently driving circulation, temperature, and precipitation changes in the $\mathrm{SH}$, these observations suggest that the SAM, as conventionally defined (i.e., based on the leading mode of SH circulation variability), may comprise a superposition of tropically forced variability upon intrinsic high-latitude variability. The focus of this paper is the role of tropical forcing in shaping the SAM, with emphasis on seasons other than summer, which have received relatively little attention in previous work.

\section{Data}

We use atmospheric fields from European Centre for Medium-Range Weather Forecasts, a combination of the 40-yr ECMWF Reanalysis (ERA-40) (1979-2002) and ERA-Interim (2003-2009) reanalysis data (Uppala et al. 2005). The two datasets show no discontinuities in the overlapping period of record (1988-2002). Because the National Centers for Environmental Prediction (NCEP2) reanalysis data (Kanamitsu et al. 2002) yield very similar results to those obtained using ECWMF data, we show only results derived from ECWMF in this study. We use sea surface temperature from the Extended Reconstructed SST version 3 (ERSSTv3) (Smith et al. 2008). Outgoing longwave radiation (OLR), obtained from the National Oceanic and Atmospheric Administration satellites, is used as a proxy for large-scale convective activity over the tropical regions (Liebmann and Smith 1996). In all calculations based on monthly mean data, the annual cycle is removed. Note that for austral summer (DJF) the year label refers to January-February. To investigate the SAM pattern on intraseasonal time scales, pentad (5 day)-mean circulation anomaly fields, from which the climatological annual (or seasonal) cycle and mean of each year (or season) have been removed, are used.

\section{Interannual variability of the SAM}

\section{a. Canonical SAM pattern at $200 \mathrm{hPa}$}

The canonical SAM pattern is usually defined as the first empirical orthogonal function (EOF) of sea level pressure or lower troposphere geopotential height fields in the SH (Hartmann and Lo 1998; Thompson and Wallace 2000; Lorenz and Hartmann 2001; Sen Gupta and England 2007). The projection of SLP or geopotential anomalies onto this EOF1 pattern then defines the timevarying SAM index. This is the method used by NOAA (http://www.cpc.ncep.noaa.gov) to define its AAO index [first EOF of 700-hPa geopotential heights poleward of $20^{\circ} \mathrm{S}$ using NCEP-National Center for Atmospheric Research (NCAR) 1979-2000 reanalysis data]. Alternatively, the SAM index can be simply defined as the difference in the normalized zonally averaged anomalies between $40^{\circ}$ and $65^{\circ} \mathrm{S}$ (Gong and Wang 1999). This approach has been used by Marshall (2003) in defining the SAM (the difference of zonal mean SLP at $40^{\circ}$ and $65^{\circ} \mathrm{S}$ based on data from the 12 stations with the longest and most complete records). 
a)Std of Z200(monthly)

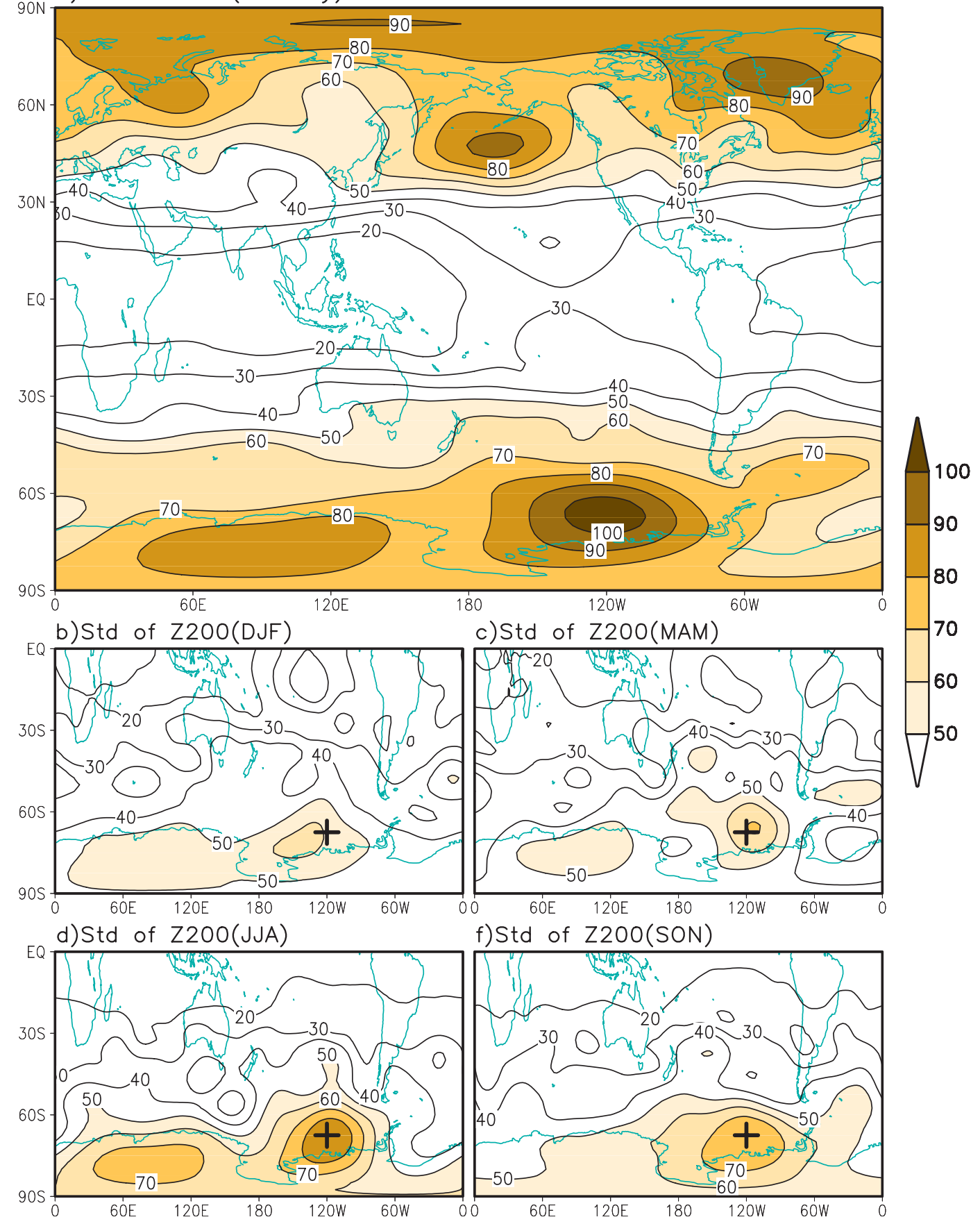

FIG. 1. Standard deviation of 200-hPa geopotential height $Z_{200}$ anomalies, 1979-2009 (ECMWF reanalysis data) for (a) monthly mean for all calendar months (b) DJF seasonal mean, (c) MAM seasonal mean, (d) JJA seasonal mean, and (e) SON seasonal mean (contour interval $10 \mathrm{~m}$ ). Cross denote the location $\left(67.5^{\circ} \mathrm{S}, 120^{\circ} \mathrm{W}\right.$ defined as the AS point hereafter) in the Amundsen Sea, where the variability of $Z_{200}$ is the largest in the SH in most seasons.

Here, we use 200-hPa geopotential heights $Z_{200}$ to define the SAM because $200 \mathrm{hPa}$ corresponds to the core of the tropospheric jet stream, where the circulation variance is greatest. The maximum variability of monthly $Z_{200}$ can be seen over West Antarctica and the
Amundsen Sea, while weaker amplitudes are observed over continental East Antarctica (Fig. 1). The strong center of action off the coast of West Antarctica, which is observed in all seasons, as well as on intraseasonal time scales, was noted by Connolley (1997), who referred to it as 
"the pole of variability". The concentration of variance in a single center of action over West Antarctica in the $\mathrm{SH}$ is distinct from the distribution of $Z_{200}$ variance in the $\mathrm{NH}$, which shows three centers of action of comparable strength: one over Greenland, one over the central North Pacific, and one over the North Pole. It has also been suggested that "the pole of variability" over West Antarctica reflects the zonally asymmetric Antarctic orography (Lachlan-Cope et al. 2001).

The leading EOF of monthly $Z_{200}$, with the data weighted by the square root of cosine of latitude to provide equal weighting of equal areas, explains $21 \%$ of the month-to-month variance south of $20^{\circ} \mathrm{S}$ and is well separated from the remaining eigenvectors according to the North et al. (1982) criterion (Fig. 2a). This pattern is very similar to EOF1 of either monthly $850-\mathrm{hPa}$ height $Z_{850}$ or sea level pressure (SLP) anomalies in the same domain. The principal component (PC) associated with EOF1 of $Z_{200}$, defined here as the SAM index (Fig. 2b), is highly correlated with the PC1 derived from $Z_{850}$ or SLP and other commonly-used indices (Table 1).

A dipole pattern with centers of action near $40^{\circ}$ and $65^{\circ} \mathrm{S}$ is the most obvious feature of the SAM. It is approximately zonally symmetric, but the zonal asymmetries are notable, and their configuration differs between the high and midlatitudes. The high-latitude band consists of two centers of variability: one over East Antarctica and one over West Antarctica, while the midlatitude outer ring is dominated by a zonal wavenumber 3 structure. A wavenumber 3 pattern is also prominent at midlatitude in the climatology (Van Loon and Jenne 1972). The strongest loading occurs over the Amundsen Sea, where the month-to-month variability is also greatest.

Prominent features of the $Z_{200}$ SAM pattern are the occurrence of two anomalous highs over the South Pacific and South Atlantic, with an anomalous low between them near the Amundsen Sea. Together, these form an arching wave train reminiscent of the Pacific-South American (PSA) teleconnection pattern that is commonly regarded as being associated with ENSO (Karoly 1989). The apparent connection with the tropical Pacific is further illustrated by the associated stationary wave activity flux, computed according to Plumb (1985) (appendix A). As shown in Fig. 2a, a prominent arc-shaped stream of wave activity flux clearly propagates away from subtropical Australia toward West Antarctica and returns to the tropics over South America, suggestive of a forced wave train embedded within the SAM.

\section{b. Seasonality of the SAM and its correlation with tropical SST}

The linkage between tropical forcing and the SAM index can also be observed in the pattern of correlations between the SAM index and SST anomalies. Figure 2c shows the correlation between the monthly SAM index and monthly SST data, while Fig. 3 shows the correlation between the seasonal mean SAM index and seasonal mean SST. (Note that the seasonal mean SAM index is simply the 3-month average of the monthly PC in each year.) The most significant correlations between the SAM and tropical SST occur during austral winter and summer, although the specific tropical region with which the SAM is most strongly correlated varies from season to season (Fig. 3). During JJA the maximum correlation between SAM and the SST variability is in the westerncentral Pacific, in the region of the subtropical convergence zone (SPCZ). In DJF the eastern Pacific from the date line to the coast of Chile is the key region linked with the SAM.

In the monthly mean data for all calendar months (Fig. 2c), the strongest correlation occurs in the central Pacific from $180^{\circ}$ to $120^{\circ} \mathrm{W}$. We estimate the significance of the correlations in Figs. 2c and 3 taking into account the autocorrelation inherent in the data, which reduces the number of degrees of freedom from 372 to about 160 (appendix B). Based on this estimate, the correlations over the central Pacific from $180^{\circ}$ to $120^{\circ} \mathrm{W}$ are significant at the 99\% confidence level (Fig. 2c). Correlations in the west-central Pacific in JJA and east-central Pacific in DJF are also significant, at $>95 \%$ confidence.

The seasonality of the amplitude and structure of the SAM can be assessed by calculating EOFs for each season individually. The annual cycle of the absolute value of the conventional monthly SAM index (inset in Fig. 2b) exhibits a pronounced maximum in the austral winter. Consistent with this result, EOF1 of monthly $Z_{200}$ primarily captures the characteristics of the SAM pattern in JJA. Likewise, of the dominant EOFs for the individual seasons, EOF1 for JJA is most similar to EOF1 of the monthly data (Fig. 4). In all seasons except summer (DJF), the pattern of EOF1 exhibits strong zonal asymmetries with the largest loading over the Amundsen Sea and neighboring regions, where the largest monthly and seasonal variability in $Z_{200}$ is observed (Fig. 1).

Let us consider how the $Z_{200}$ variability over this region of high variability is linked with the $\mathrm{SH}$ circulation as a whole. Regression maps between the point with the largest variance [denoted as "AS" (at $67.5^{\circ} \mathrm{S}, 120^{\circ} \mathrm{W}$ ) in Fig. 1] and $\mathrm{SH} Z_{200}$ display a prominent wave train pattern emanating from the tropical central Pacific and propagating to the Amundsen Sea (Fig. 5). These onepoint regression maps strongly resemble the corresponding leading EOF for the respective seasons, thus suggesting that the EOFs are dominated by the circulation variability over the Amundsen Sea. As shown in Fig. 5, $Z_{200}$ over the Amundsen Sea is also significantly correlated with tropical 


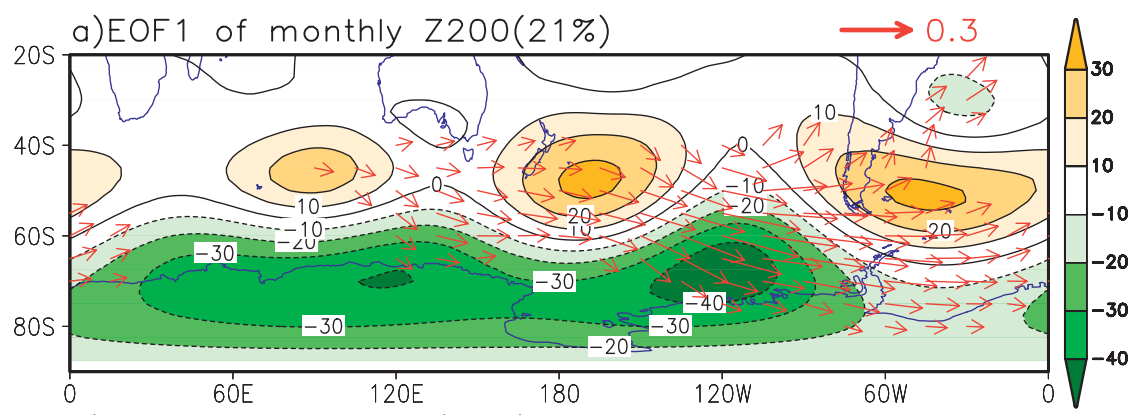

b) Monthly SAM index(PC1)

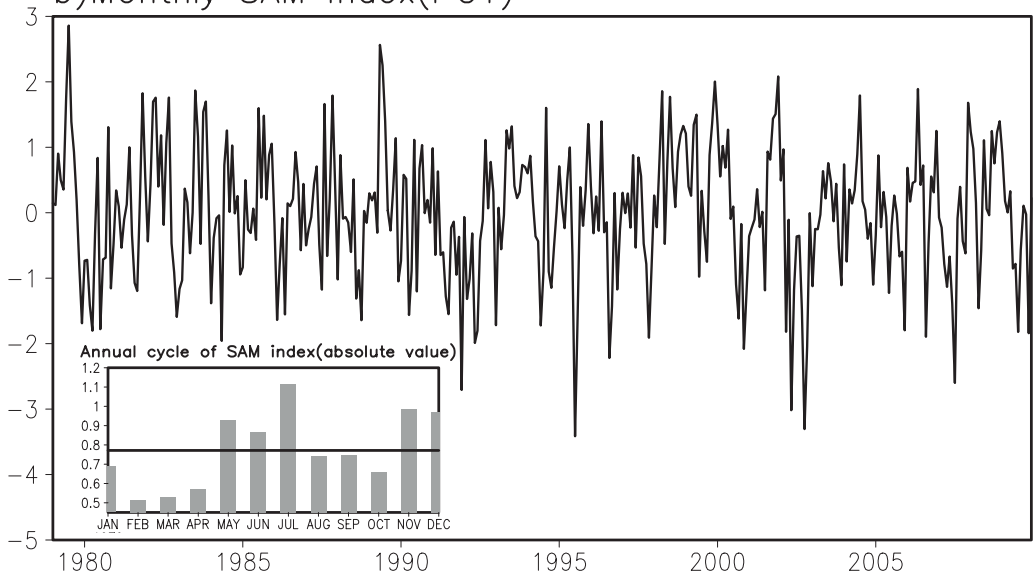

c) Corr. of SAM index with SST

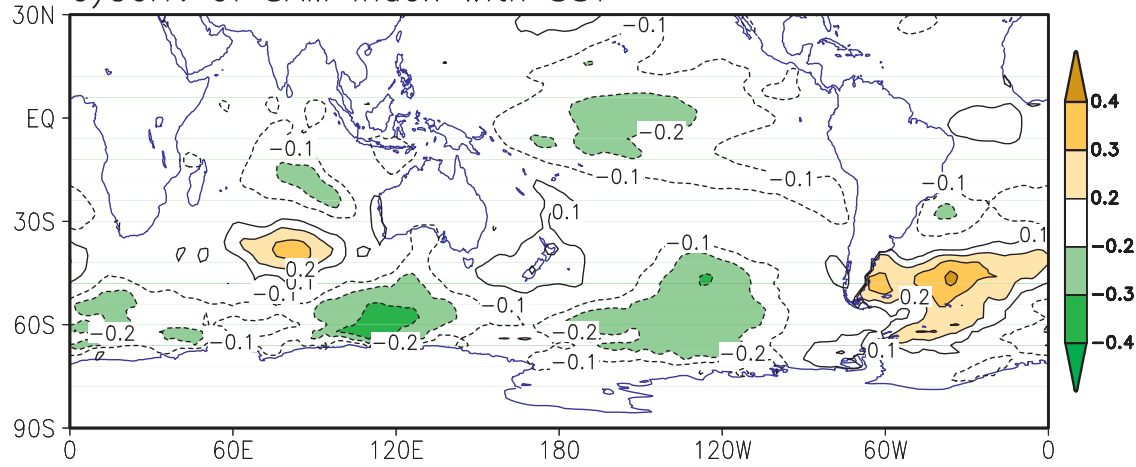

FIG. 2. (a) EOF1 of 31-yr (1979-2009) monthly mean SH 200-hPa height anomalies based on data for all calendar months (contour interval $10 \mathrm{~m}$ ). EOF1, explaining $21 \%$ of total variance, has been scaled by one standard deviation of the corresponding principal component. The red vectors (unit $10^{6} \mathrm{~m}^{2} \mathrm{~s}^{-2}$ ) denote the wave activity flux associated with the EOF1 pattern (see appendix A for details). Wave vectors with both components less than $0.1 \times 10^{6} \mathrm{~m}^{2} \mathrm{~s}^{-2}$ are omitted. (b) Principal component of EOF1 (PC1). The inset shows the annual cycle of the amplitude of PC1 defined as the 31-yr average of the absolute value of PC1 for each month. The solid line denotes the mean of the annual cycle. (c) Correlation between PC1 and global monthly mean SST for the period 1979-2009. Significant correlations above $99 \%$ confidence level are highlighted by shading.

Pacific SST in all seasons. The related SST pattern is very similar to that associated with the seasonal SAM index (Fig. 3). The region of maximum correlation in the SST field appears in each season to be directly associated with the wave-train-like pattern in $Z_{200}$. In DJF the strongest correlation with SST occurs in the eastern tropical Pacific, and the wave train pattern in $Z_{200}$ assumes the form of a meridionally oriented dipole, whereas in the other seasons the wave train pattern follows a "great circle" path emanating from the western and central tropical Pacific. In each of those seasons, the maximum correlation with SST is also located in the tropical central Pacific.

The pattern of SST and $Z_{200}$ correlations in Fig. 5 suggests that the regions of maximum SST correlation (denoted by the boxes in Fig. 5) are key regions in the tropical Pacific for exciting the Rossby wave response 
TABLE 1. Correlation coefficient between PC1 of monthly $Z_{200}$ in the SH $\left(87.5^{\circ}-20^{\circ} \mathrm{S}\right)$ and PC1 of monthly $Z_{850}$ and PC1 of SLP in the same domain, and monthly SAM indices derived from NOAA and Marshall (2003) for the period 1979-2009.

\begin{tabular}{ccccc}
\hline \hline & $\begin{array}{c}\text { PC1 of } \\
Z_{500}\end{array}$ & $\begin{array}{c}\text { PC1 of } \\
\text { SLP }\end{array}$ & $\begin{array}{c}\text { NOAA AAO } \\
\text { index }\end{array}$ & $\begin{array}{c}\text { Marshall SAM } \\
\text { index }\end{array}$ \\
\hline PC1 of $Z_{200}$ & 0.94 & 0.92 & 0.93 & 0.75
\end{tabular}

that characterizes the PSA pattern, as has been shown previously, for example, by Karoly (1989). This relationship is further illustrated in Fig. 6, which shows the correlation between tropical Pacific SST over these key regions and SLP. The correlation between those tropical SST anomalies and the low-level circulation exhibits a PSAlike wave train structure in the extratropics, with a phase reversal between the upper and lower troposphere over the tropical Pacific, indicative of a stationary Rossby wave response to tropical SST forcing.

\section{c. Decomposition of the SAM into regional patterns}

Previous work has shown that the North Hemisphere annular mode may represent a superposition of regional patterns (Cash et al. 2002; Cohen and Saito 2002; Gerber and Vallis 2005; Kushner and Lee 2007). To examine the similar possible superposition for the SAM, we attempt to remove the impact of the PSA wave train upon the SAM to the extent that this is possible. For this purpose, the variability that is linearly related to $Z_{200}$ at the point "AS" over the Amundsen Sea in Fig. 1 is removed from the monthly $Z_{200}$ time series at each SH grid point using the least squares fitting method (e.g., Van den Dool et al. 2000). This is equivalent to removing a PSA-shaped wave train from each monthly $Z_{200}$ field. By construction, the variability over the AS point and the neighboring region is almost entirely eliminated, while the variability over remote areas that is unrelated to the AS point is retained. On average, $13 \%$ of the total variability south of $20^{\circ} \mathrm{S}$ is removed by this procedure. EOF1 of the residual monthly data exhibits a pattern that is distinct from EOF1 of the raw data, with a zonal dipole pattern that is well defined only in the Eastern Hemisphere (Fig. 7a).

The time-varying index of the pattern in Fig. 7a exhibits strongest variability during the cold season (Fig. 7b). The correlation between the seasonal-mean index of this pattern and simultaneous SST anomalies (Fig. 8) reveals

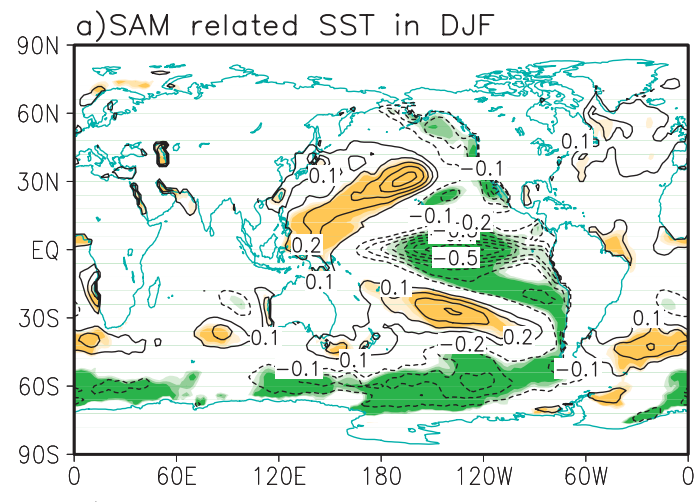

b) SAM related SST in MAM
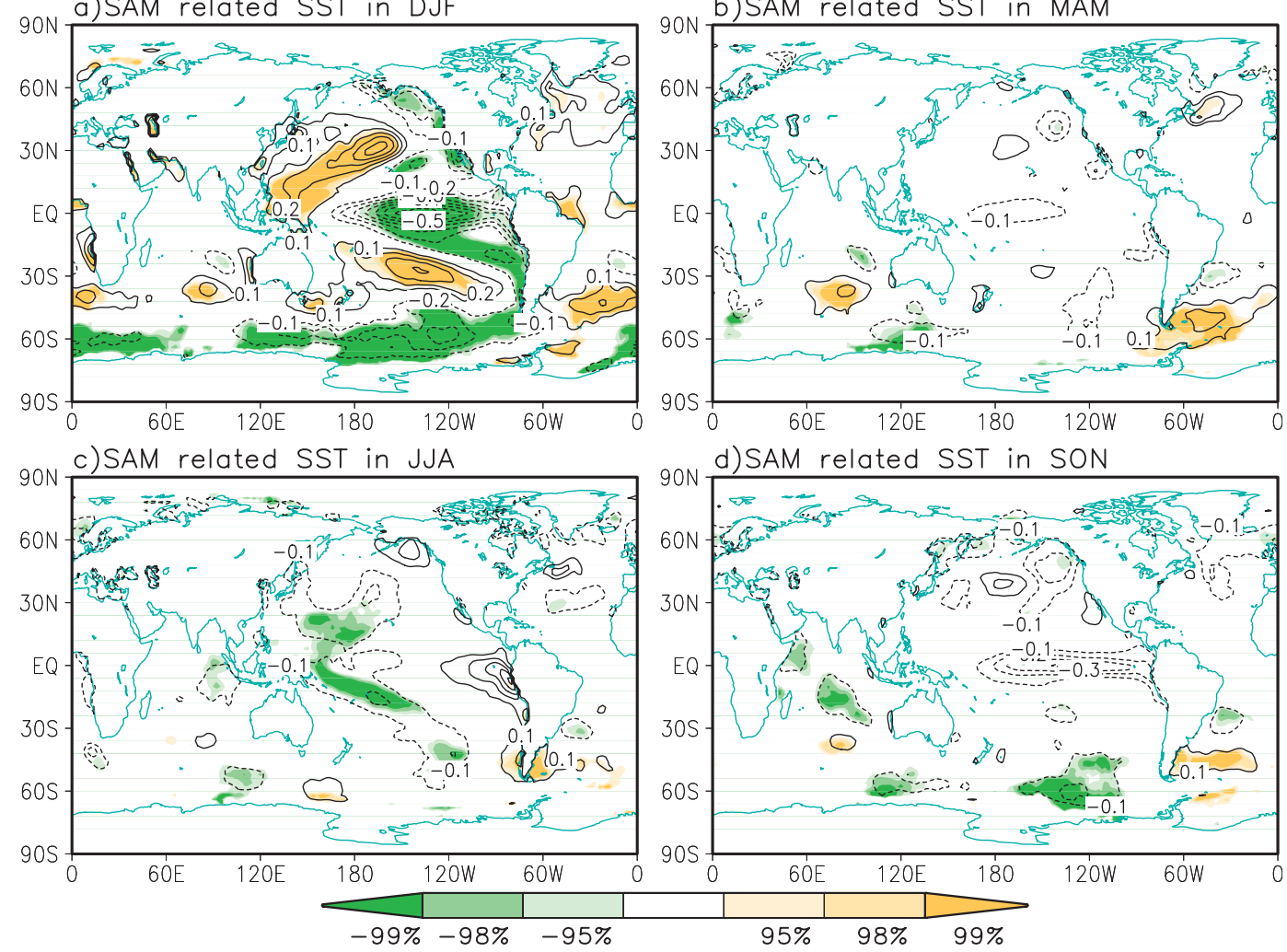

FIG. 3. Regression of the seasonal mean SAM index against seasonal mean SST anomalies (contour interval $0.1^{\circ} \mathrm{C}$ ) for (a) DJF, (b) MAM, (c) JJA, and (d) DJF. Shading denotes regions in which correlation is significant at or above the $95 \%$ confidence level. 

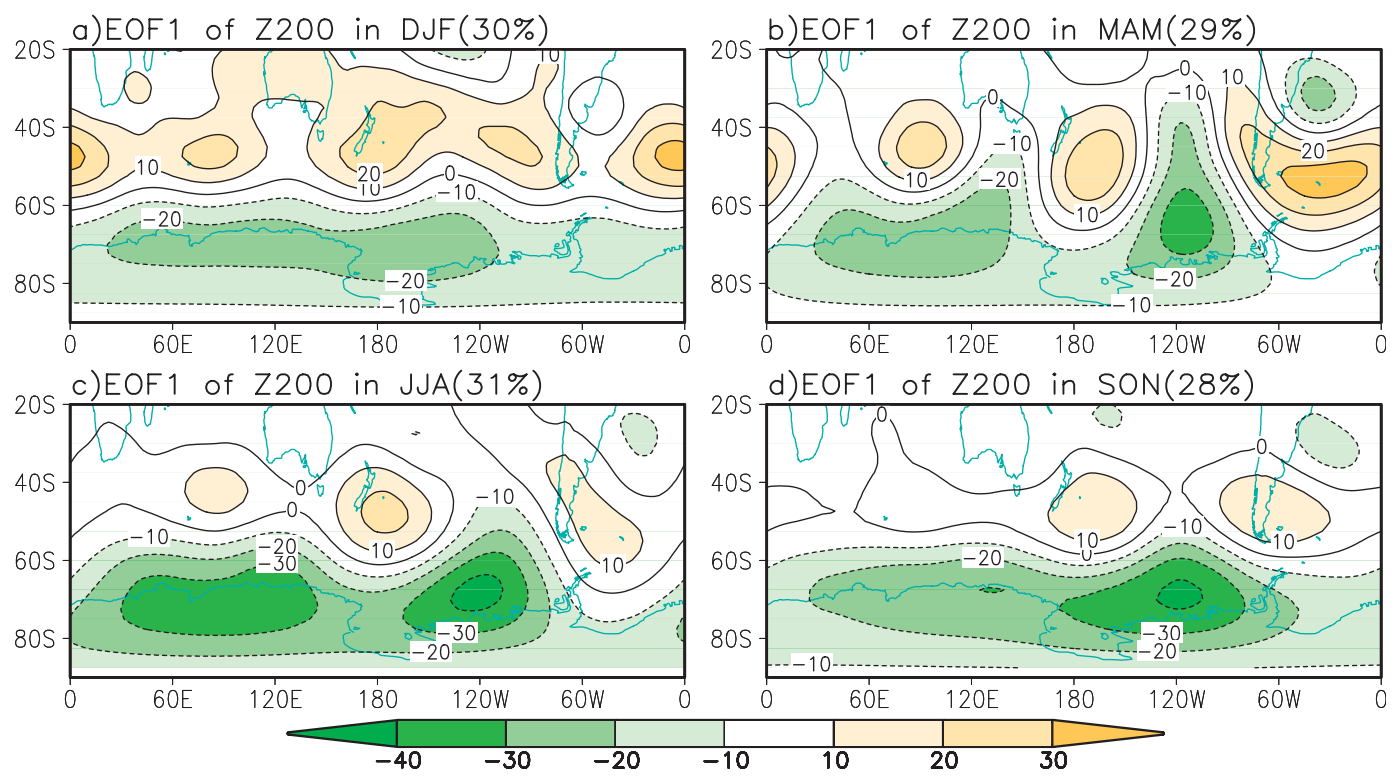

FIG. 4. EOF1 of 31-yr (1979-2009) (a) DJF, (b) MAM, (c) JJA, and (d) SON seasonal mean SH 200-hPa height anomalies (contour interval 10m). EOF1 has been scaled by one standard deviation of the corresponding principal component. The percentage of the total variance explained by EOF1 is indicated on the top of each panel.

a close connection between this regional SAM and tropical SST anomalies in the warm pool and SPCZ region in JJA and SON. In the other two seasons the connection with the tropics is very weak. Thus, the SAM in the Indian Ocean sector is also related to tropical SST anomalies in winter and spring, but the key tropical region is located to the west of the SST anomalies that are related to the PSA, as shown in Fig. 5c.

The foregoing analysis suggests that the SAM patterns in the Eastern and Western Hemispheres are independent. To further test this idea, the difference between the normalized zonal mean $Z_{200}$ anomalies along $40^{\circ}$ and $65^{\circ} \mathrm{S}$ is computed separately for the Eastern and Western Hemispheres bounded by the $180^{\circ}$ and $0^{\circ}$ meridians. As shown in Table 2, the correlation between the indices for the Eastern and Western Hemispheres is weak and varies erratically from one calendar month to the next. In a seasonal mean sense, the connection between the SAM-related variability in the two sectors is significant in summer (DJF) and spring (SON) but not in fall [MarchMay (MAM)] and winter (JJA). Analogous tables (not shown) were constructed using other longitudes for partitioning the two hemispheres. The weakest interhemispheric correlations are obtained when the Pacific sector is separated from the Indian Ocean sector. Thus, the zonal homogeneity and coherence of the SAM are not robust throughout the year.

The SAM-related fluctuations over the Pacific and Indian Ocean sector have a stronger tendency to behave independently in the upper troposphere than at lower levels. Analogous calculations based on the $Z_{500}$ field indicate that the regional SAM indices exhibit similar independence in the midtroposphere. At the surface the zonal coupling is somewhat stronger. However, the strong zonal symmetry of SAM in the SLP field is mainly a reflection of the zonal coherence of SLP primarily at high latitudes. At midlatitudes (e.g., along $40^{\circ} \mathrm{S}$ ) SLP is not significantly correlated between the two sectors except during DJF (Table 3).

Figure 9 shows the 1-month-lag autocorrelation of the monthly $Z_{200}$ in the SH. The tropical $Z_{200}$ shows large autocorrelation, indicating strong month-to-month persistence of tropical circulation resulting from slowly varying tropical SSTs. In the midlatitudes of the Indian Ocean, $Z_{200}$ shows very little persistence. In contrast, $Z_{200}$ over the Pacific show relatively large persistence at midlatitudes. The largest autocorrelation of $Z_{200}$ is observed adjacent to and over West Antarctica, and this high autocorrelation appears to connect to the tropics through the South Pacific. These results offer additional evidence that high-latitude circulation variability over the Pacific sector and Indian Ocean sector have quite different origins, with a strong tropically related process prevailing in the Pacific and a midlatitude-related processes dominating in the Indian sector. This is consistent with the results of Barnes and Hartmann (2010), who found that in JJA a positive eddy feedback that acts to sustain the SAM is observed over the Indo-Atlantic sector but not over the Pacific sector. Barnes and Hartmann further suggested that the lack of wintertime eddy feedback over the South 

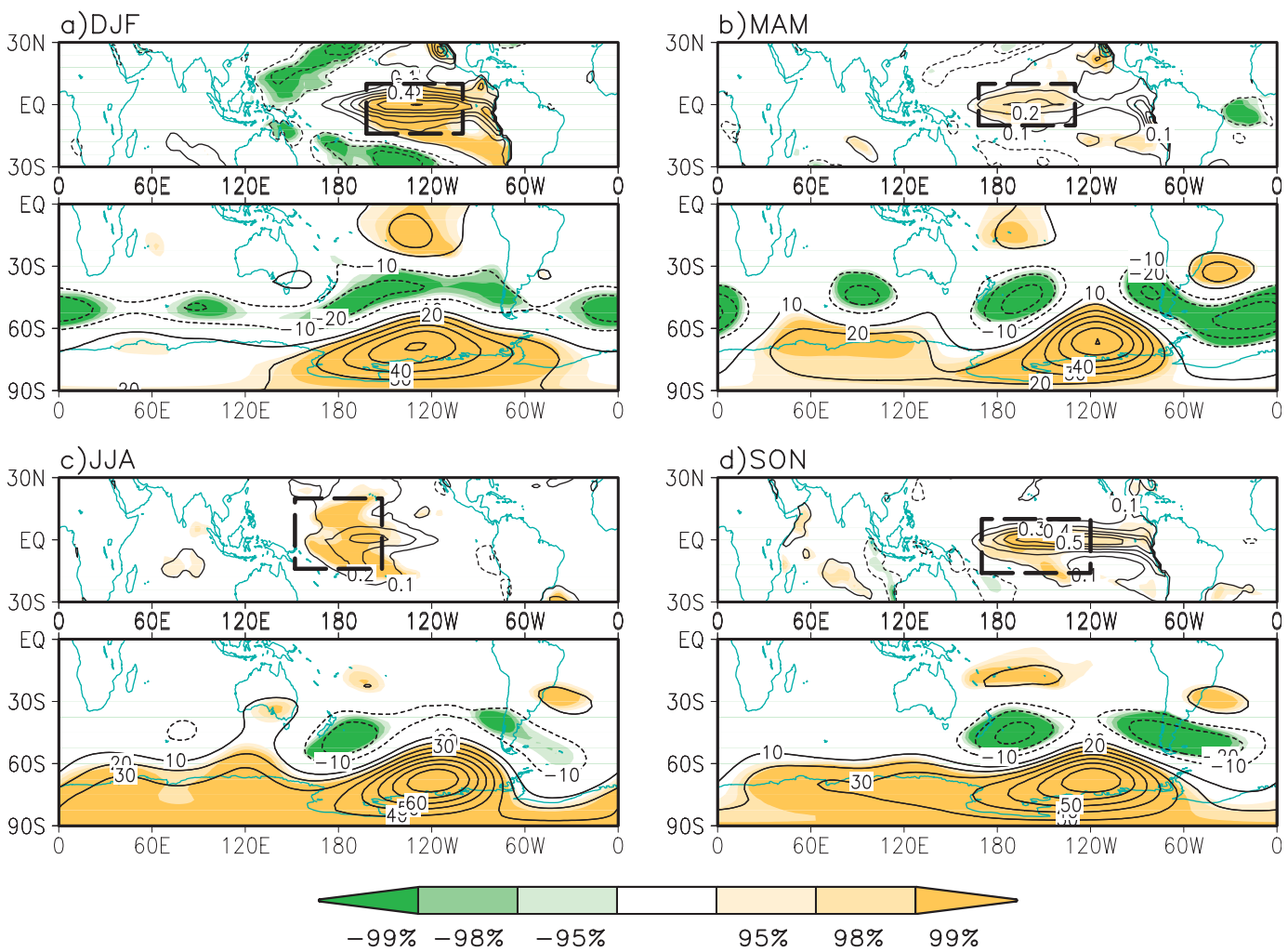

FIG. 5. Regression of $Z_{200}$ over the AS point $\left(67.5^{\circ} \mathrm{S}, 120^{\circ} \mathrm{W}\right)$ in the Amundsen Sea against (top) tropical SST (contour interval $0.1^{\circ} \mathrm{C}$ ) and (bottom) SH $Z_{200}$ (contour interval $10 \mathrm{~m}$ ) for (a) DJF, (b) MAM, (c) JJA, and (d) DJF. Shading denotes regions in which correlation is significant at or above the $95 \%$ confidence level.

Pacific is due to the absence of the midlatitude jet in that region.

The results presented above indicate that the leading EOF mode of SH circulation variability, conventionally defined as the SAM, owes its existence to a superposition of two largely independent patterns: a PSA wave train over the Pacific sector that projects upon the zonally symmetric SAM signature and a north-south shifting of the jet stream and storm track over the Indian Ocean sector that is a reflection of extratropical eddy-mean flow interaction.

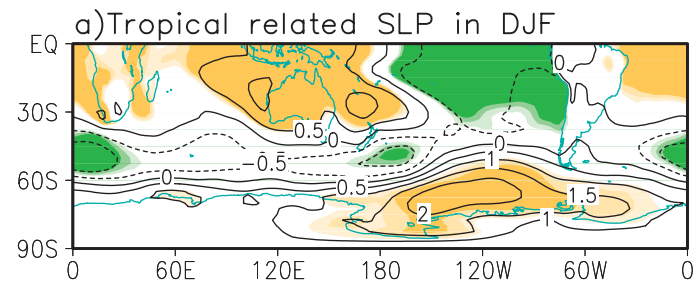

b) Tropical related SLP in MAM
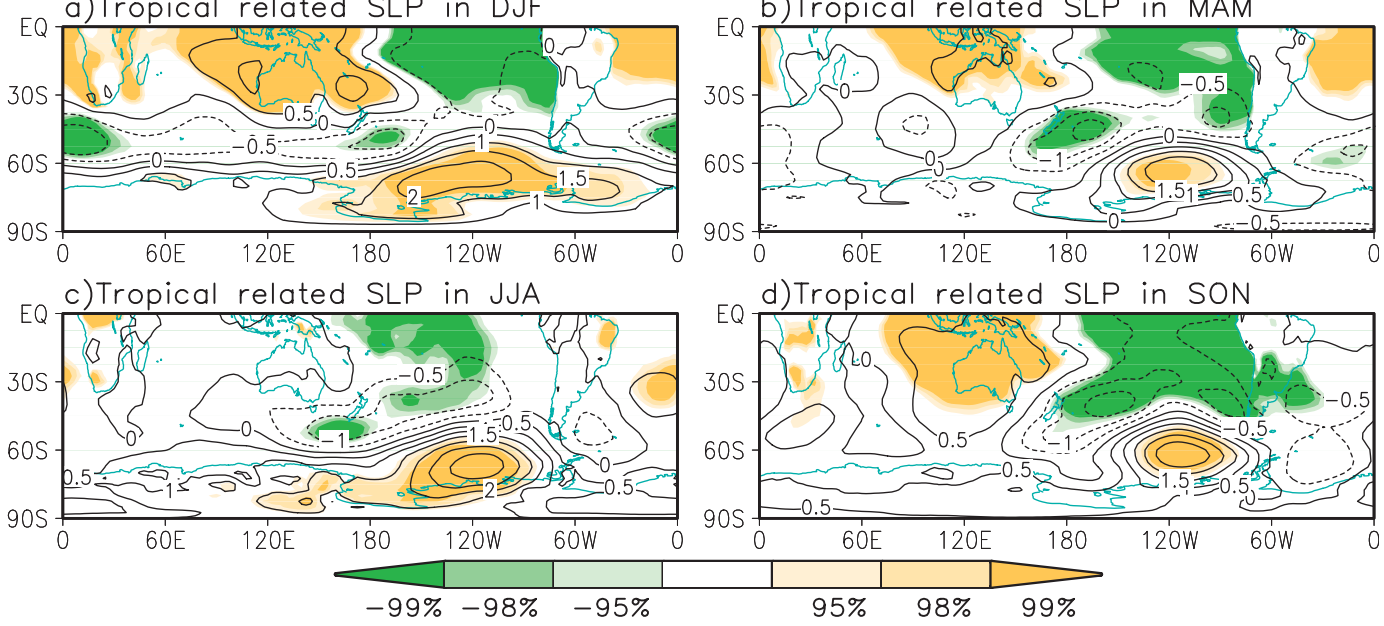

d) Tropical related SLP in SON

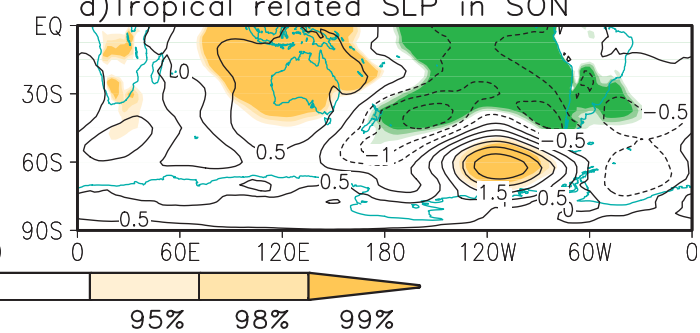

FIG. 6. Regression of tropical SST over the key region (denoted as the box in Fig. 5 in the corresponding season) against SH SLP anomalies (contour interval $0.5 \mathrm{hPa}$ ) for (a) DJF, (b) MAM, (c) JJA, and (d) DJF. Shading denotes regions in which correlation is significant at or above the $95 \%$ confidence level. 


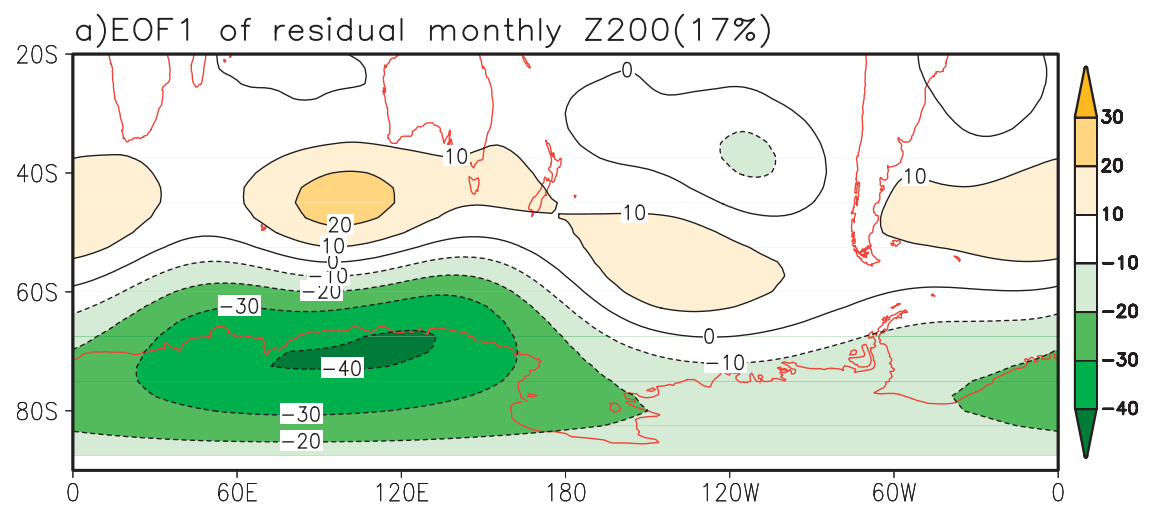

b)Annual cycle of PC1(absolute value)

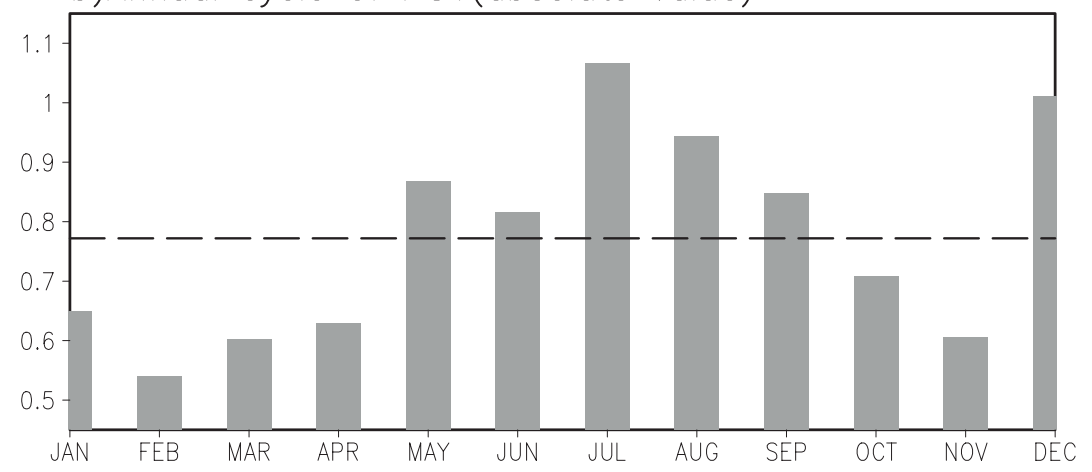

FIG. 7. (a) EOF1 of 31-yr (1979-2009) residual monthly mean SH $200 \mathrm{hPa}$ height anomalies (contour interval 10m). EOF1 has been scaled by one standard deviation of the corresponding principal component. (b) Annual cycle in the amplitude of associated PC1 defined as the 31-yr average of the absolute value of PC1 in each month. Dashed line denotes the mean of the annual cycle.

Only during DJF is a significant relationship observed between the SAM in the Pacific sector and the meridionally oscillating contribution to the SAM in the Indian Ocean sector. A positive feedback of the stationary waves upon zonal-mean flow, as suggested by DeWeaver and Nigam (2000), is one mechanism that might cause these two separate patterns to occasionally vary in tandem.

\section{Trends involving the covariability of the SAM and tropical SST}

\section{a. Epochal differences in the SH circulation and the tropical SST field}

Most research on the trend in the SAM has focused on the observed positive trend during austral summer and its association with both global tropospheric greenhouse gas forcing and high-latitude SH stratospheric ozone forcing (Thompson and Solomon 2002; Gillett and Thompson 2003; Marshall et al. 2004; Shindell and Schmidt 2004; Arblaster and Meehl 2006; Miller et al. 2006). In view of the close connection between variations in tropical SST and the SAM discussed above, it is of interest to explore the possible role of trends in tropical SST in contributing to the observed trend in the SAM.

The monthly index of the SAM derived from EOF1 of $Z_{200}$ for all calendar months exhibit no significant trend since 1979 (Fig. 2a). However, a positive trend is clearly discernible in the seasonal index for DJF (Fig. 10a), in agreement with previous work. The shift in the SAM index mainly occurs in the mid-1990s. In contrast, a decreasing trend is observed in JJA that has not previously been discussed in the literature (Fig. 10c). While the magnitude of the trend is sensitive to the end points, due to the high interannual variability, it is marginally significant at the $95 \%$ confidence level. Much of the decrease in the index in JJA occurred around 1990. During spring and fall, there is no apparent trend in the SAM index.

To illustrate the spatial patterns of the trends in winter and summer, based on the corresponding seasonal SAM index, the 1979-2009 period of record can be divided subjectively into the two epochs that exhibit the largest contrast. Epochal differences in $Z_{200}$ between 1979-93 and 1994-2009 for DJF and between 1979-89 and 19902009 for JJA are shown in Fig. 11. The $Z_{200}$ epochal differences in Fig. 11 exhibit contrasting polarities of the 

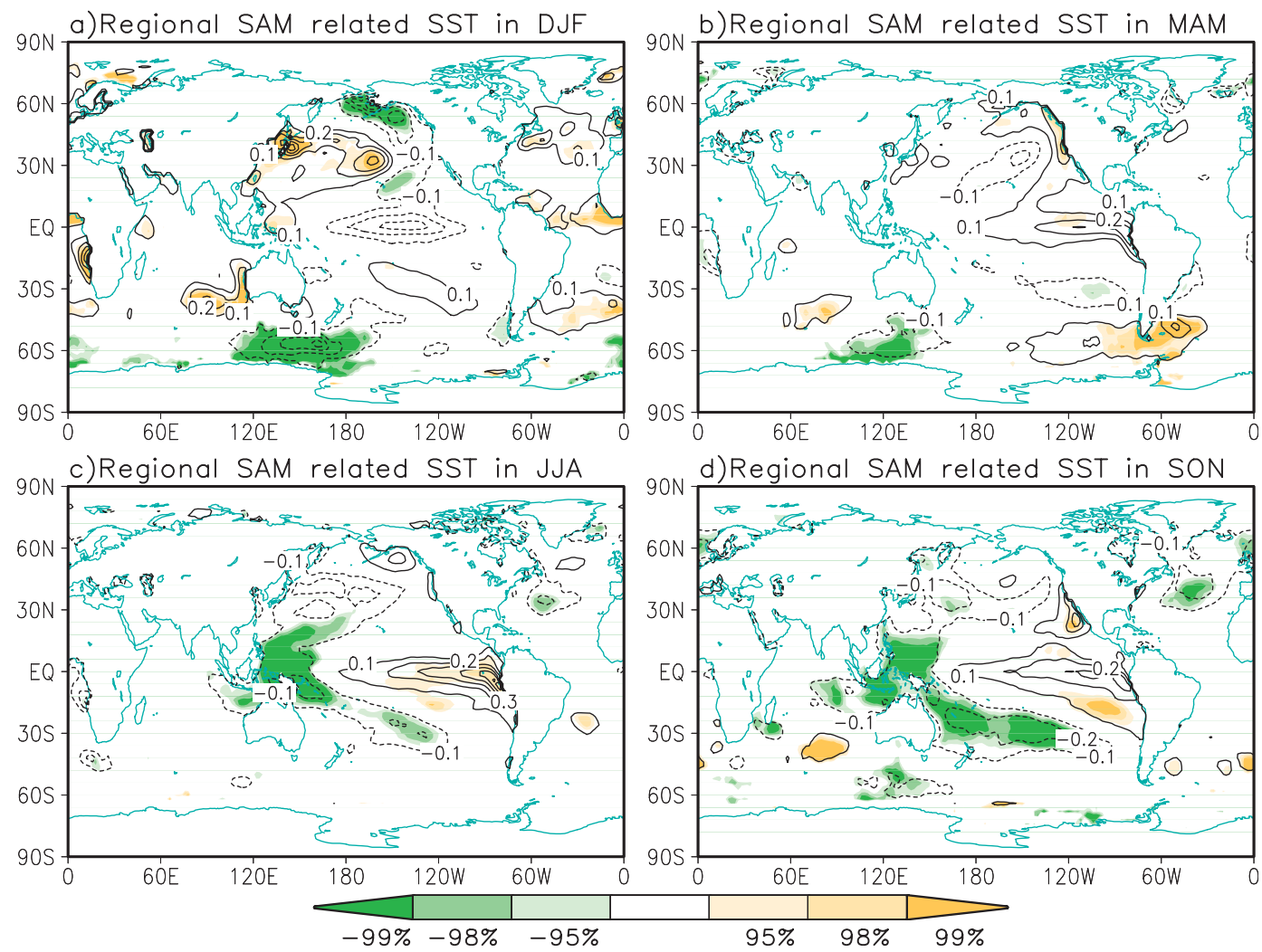

FIG. 8. Regression of seasonal mean PC1 of residual monthly mean SH 200-hPa height anomalies (Fig. 7) against seasonal mean SST anomalies (contour interval $0.1^{\circ} \mathrm{C}$ ) for (a) DJF, (b) MAM, (c) JJA, and (d) DJF. Shading denotes regions in which correlation is significant at or above the $95 \%$ confidence level.

SAM. In DJF a pronounced zonally symmetric dipole dominates the circulation difference (Fig. 11a). In JJA $Z_{200}$ increases almost everywhere in the SH from the earlier to the later epoch with the greatest increases occurring over the Amundsen Sea and West Antarctica (Fig. 11b). The PSA wave train pattern that was noted in the interannual variability can be traced from West Antarctica back to subtropical Australia in the $Z_{200}$ difference pattern for JJA. Similar changes are observed in the middle troposphere and at the surface, as shown in Ding et al. (2011, their Fig. 1).

The tropical SST change between the two selected epochs shows a significant warming in the central Pacific/

TABLE 2. Correlation between Eastern and Western Hemisphere components of the difference between normalized zonal mean $Z_{200}$ (ECMWF reanalysis data, 1979-2009) at $40^{\circ}$ and $65^{\circ} \mathrm{S}$. Significant correlations above $95 \%$ confidence level are bold.

Dec Jan Feb Mar Apr May Jun Jul Aug Sep Oct Nov $\begin{array}{llllllllllll}\mathbf{0 . 4 7} & \mathbf{0 . 5 7} & 0.12 & 0.24 & 0.11 & \mathbf{0 . 4 3} & 0.33 & \mathbf{0 . 4} & 0.08 & 0.19 & \mathbf{0 . 4 2} & 0.23\end{array}$

\begin{tabular}{|c|c|c|c|}
\hline DJF & MAM & JJA & SON \\
\hline 0.48 & 0.15 & 0.27 & 0.49 \\
\hline
\end{tabular}

SPCZ in JJA and a cooling in the eastern Pacific in DJF (Figs. 11c,d). These two tropical regions with significant SST change in JJA and DJF, respectively, are also the regions in which the interannual SST anomalies are closely coupled with the Pacific component of the SAM in the corresponding seasons. On the interannual time scales, the positive SST anomalies over these two regions corresponds to the negative polarity of the SAM, Thus, the sign of the SST trends in these regions matches the sign of the SH circulation trends, consistent with the relationships for the year-to-year variability discussed in the previous section.

The upper-tropospheric circulation is more sensitive to the subtle change in the tropics than the flow at lower levels; hence the upper-level divergence associated with

TABLE 3. Correlation between Eastern and Western Hemisphere components of the zonal mean normalized SLP (ECMWF reanalysis data, 1979-2009) along $40^{\circ} \mathrm{S}$. Significant correlations above $95 \%$ confidence level are bold.

Jan Feb Mar Apr May Jun Jul Aug Sep Oct Nov Dec

$\begin{array}{llllllllllll}\mathbf{0 . 5 7} & \mathbf{0 . 5 7} & \mathbf{0 . 4 5} & \mathbf{0 . 5 6} & 0.10 & 0.01 & 0.02 & -0.18 & -0.21 & 0.19 & 0.29 & \mathbf{0 . 3 7}\end{array}$ 


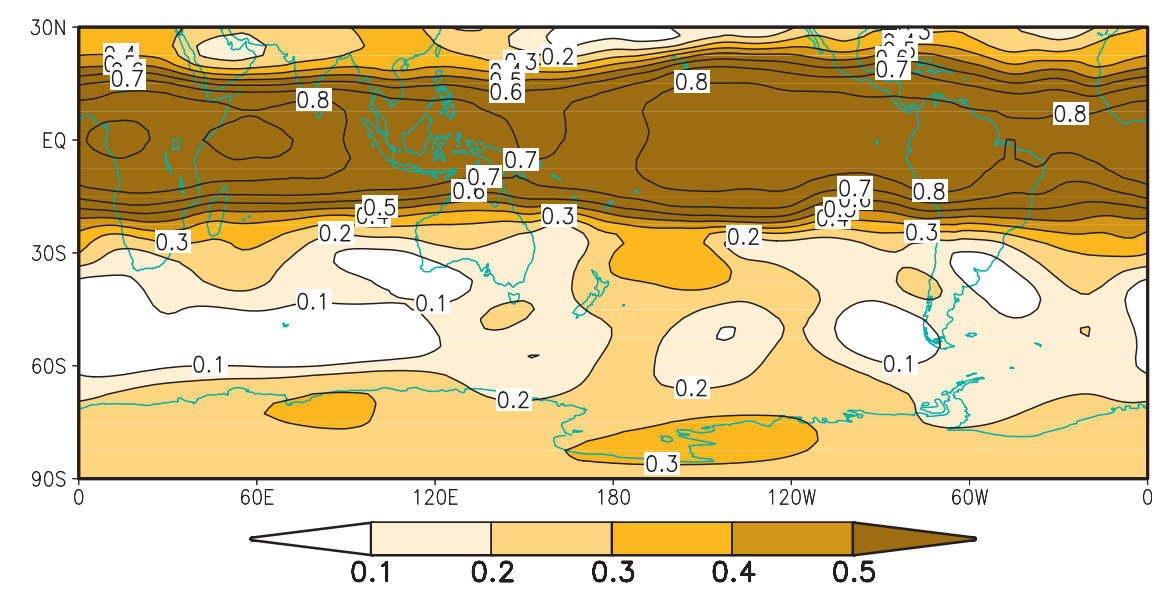

FIG. 9. One-month-lag autocorrelation of monthly $Z_{200}$ in the SH.

the tropical forcing plays a key role in driving tropicalextratropical teleconnections (Hoskins and Karoly 1981; Sardeshmukh and Hoskins 1988; Trenberth et al. 1998). The changes in tropical outgoing longwave radiation (OLR) and velocity potential that are coincident with the trend in the SAM are plotted in Figs. 11e,f. Accompanying the JJA SST warming in the tropical central Pacific and SPCZ region, an increase in convection and upper-level divergence took place from the 1980s to the subsequent two decades, while in DJF convection and upper-level divergence decreased over the SST cooling region in the central eastern Pacific. These long-term changes in upper-level divergence, which appears to be directly driven by the forcing at the lower boundary, may play a key role in forcing the extratropical trends.

\section{b. MCA analysis}

In the previous section, we showed the calculated epochal difference for JJA and SON. The choice of which two periods to use in making epochal difference, while subjective, is useful in illustrating the patterns associated with the largest changes in high-latitude circulation. To provide an objective analysis, we employ maximum covariance analysis (MCA) (see appendix C for details) a) Seasonal mean SAM index(DJF)

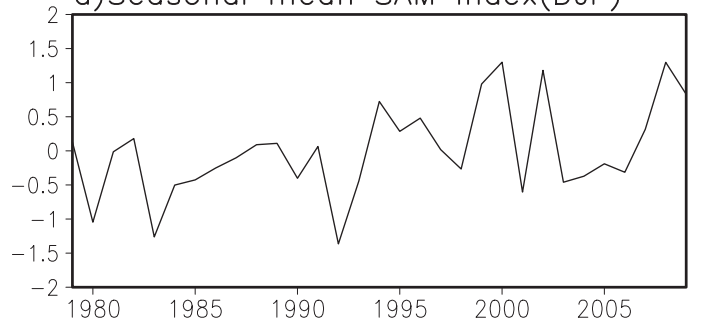

c) Seasonal mean SAM index(JJA)

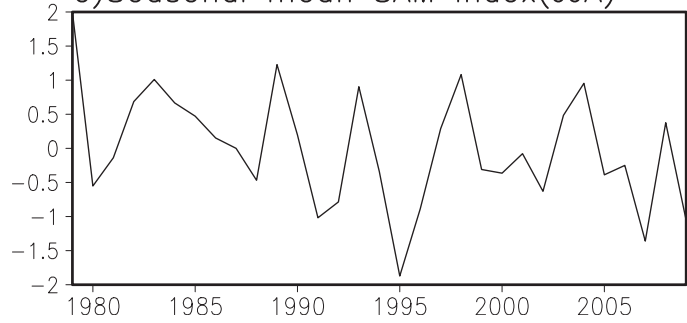

b) Seasonal mean SAM index(MAM)

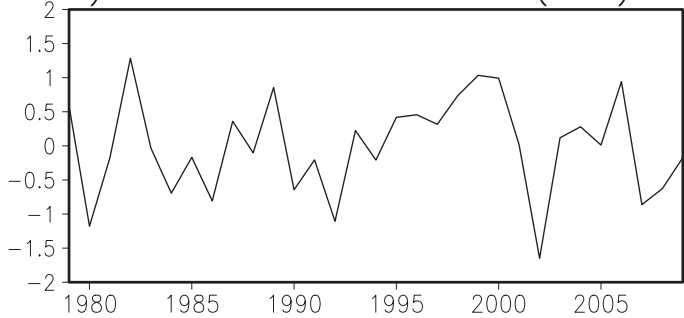

d) Seasonal mean SAM index(SON)

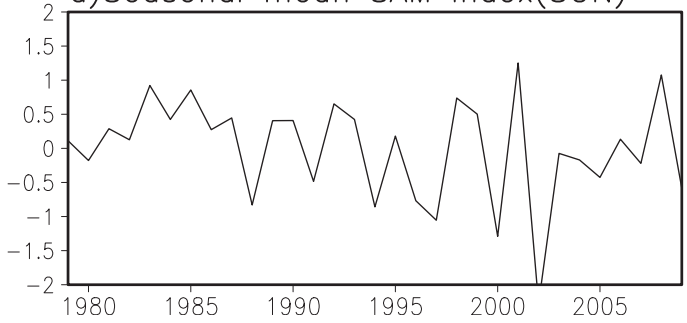

FIG. 10. Seasonal mean SAM index derived from PC1 of original monthly EOF1 (Fig. 2) for (a) DJF, (b) MAM, (c) JJA, and (d) SON. The temporal evolution of SAM in DJF can be divided subjectively into two epochs (1979-93 and 1994-2009) that have the largest contrast. For JJA, the entire period can be divided into 1979-89 and 1990-2009. Note that the upward trend in DJF is significant at the $98 \%$ confidence level and the downward trend in JJA is marginally significant at the $95 \%$ confidence level by Mann-Kendall test (Kendall 1955) and trend-to-noise ratio test (Wilks 1995). 

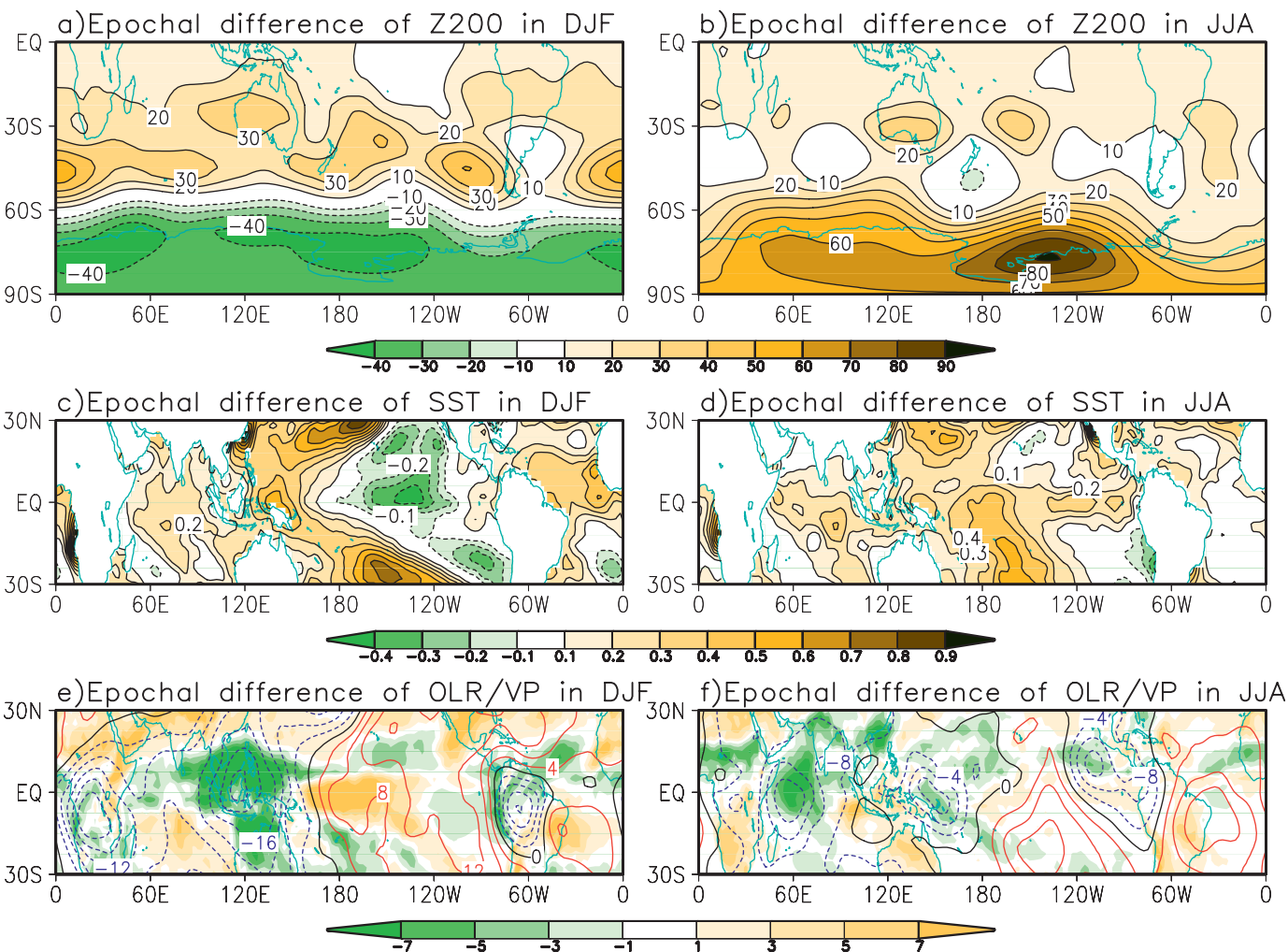

FIG. 11. Epochal differences (1994-2009 minus 1979-93) of DJF mean (a) SH $Z_{200}$ (contour interval $10 \mathrm{~m}$ ), (c) tropical SST (contour interval $0.1^{\circ} \mathrm{C}$ ), and (e) tropical OLR (shading interval $2 \mathrm{~W} \mathrm{~m}^{-2}$ ) and $200 \mathrm{hPa}$ velocity potential (contour interval $2 \times 10^{5} \mathrm{~m}^{2} \mathrm{~s}^{-1}$ ). Epochal differences (1990-2009 minus 1979-89) of JJA mean (b) SH $Z_{200}$ (contour interval $10 \mathrm{~m}$ ), (d) tropical SST (contour interval $0.1^{\circ} \mathrm{C}$ ), and (f) tropical OLR (shading interval $2 \mathrm{~W} \mathrm{~m}^{-2}$ ) and 200-hPa velocity potential (contour interval $2 \times 10^{5} \mathrm{~m}^{2} \mathrm{~s}^{-1}$ ).

of the seasonal mean tropical SST and SH $Z_{200}$ for the period 1979-2009, carried out separately for JJA and DJF. Results obtained from the MCA consist of modes comprising paired spatial patterns of SST and $Z_{200}$ and the corresponding expansion coefficient time series. The leading mode indicates the pattern of tropical SST anomalies that is most strongly coupled with the $\mathrm{SH}$ circulation and the $\mathrm{SH}$ circulation anomalies associated with that pattern.

For both seasons the leading MCA modes are dominated by an ENSO-related coupled pattern, which is particularly strong during DJF (Figs. 12 and 13 ). The corresponding time series are dominated by interannual variability and exhibit negligible linear trends over the 31-yr record. Hence, the canonical eastern Pacific ENSO-related variability does not contribute (at least not directly) to the observed long-term changes in the $\mathrm{SH}$ circulation. In contrast, the second MCA modes in both seasons capture the long term trends in the circulation and the related trends in tropical SST. In summer (DJF), SST cooling over the eastern Pacific and warming over most of the remainder of the tropics occurs in association with an annular trend in $Z_{200}$ (Fig. 12b). In winter (JJA) a PSA-like trend in $Z_{200}$ occurs in association with a significant warming of SST over the tropical central Pacific/SPCZ region (Fig. 13b), as shown previously by Ding et al. (2011). The $Z_{200}$ and SST patterns in the second mode closely resemble the epochal differences in $Z_{200}$ and SST, respectively, in both JJA and DJF as shown in Fig. 11. The associated time series exhibit significant long term trends very similar to those in the respective time series of the seasonal SAM index shown in Fig. 10. In particular, the time series of SST and $Z_{200}$ in the JJA mode exhibit a steady increase during the first half of the record and SST and $Z_{200}$ in the DJF mode both show a shift around the mid-1990s. The MCA thus captures the salient features of the covariability between the $\mathrm{SH}$ circulation trend and concurrent changes in the tropical SST and further supports our interpretation of their statistical relationship. We note that, because the strong interannual variability associated with ENSO is captured in the first mode of the maximum covariance analysis, the trend of SH circulation associated with the second 
a) DJF mode 1 SCF $=83 \%$

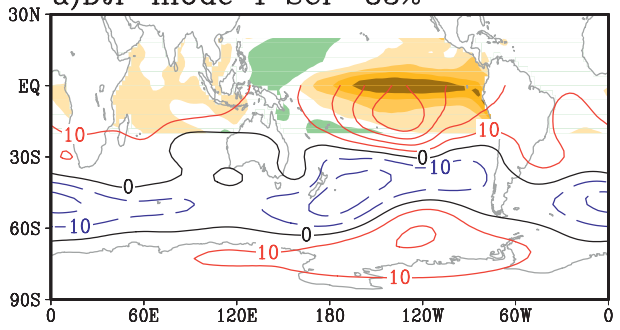

c)Timeseries of DJF mode $1 \mathrm{r}=0.92$

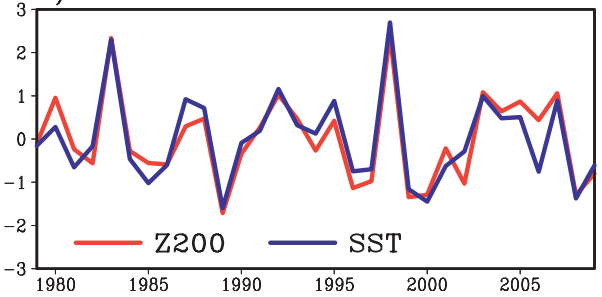

b) DJF mode $2 \mathrm{SCF}=13 \%$
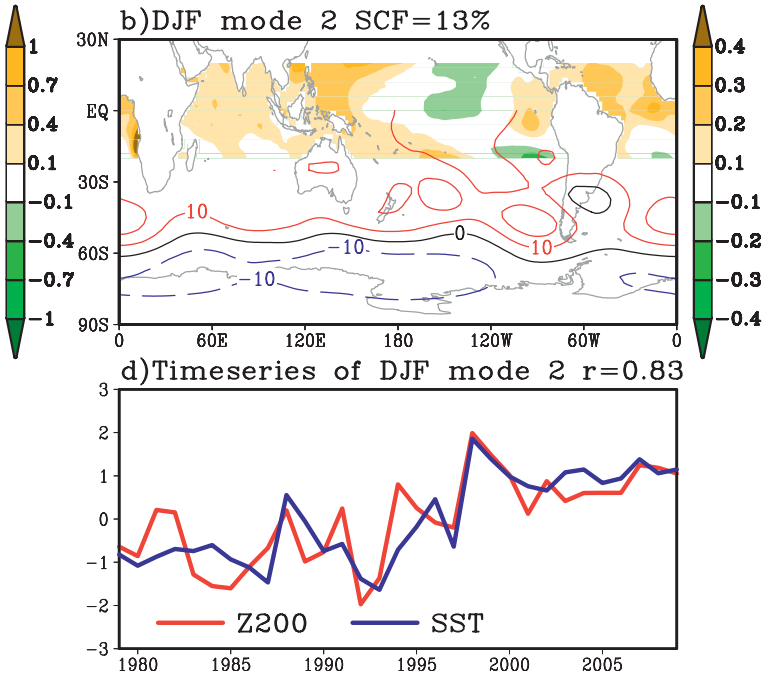

FIG. 12. Principal modes of covarying tropical sea surface temperature and Southern Hemisphere circulation in austral summer (DJF). Spatial patterns of tropical SST (shading) and 200-hPa geopotential heights $\left(Z_{200}\right.$, contour interval $10 \mathrm{~m}$ ) associated with (a) mode 1 and (b) mode 2. Time series of SST and $Z_{200}$ for (c) mode 1 and (d) mode 2. Amplitudes in (a),(b) are scaled by one standard deviation of the corresponding time series in (c),(d). (top) SCF (squared covariance fraction) and the temporal correlation coefficient $r$ between the two expansion coefficient time series are indicated. Note that the upward trends in both time series in mode 2 are significant at the $99 \%$ confidence level by Mann-Kendall test and signal-to-noise ratio test.

mode has greater statistical significance than the SAM index.

\section{Dynamical interpretation}

\section{a. Dynamics of interannual variability of the $S A M$ in the Pacific sector}

The empirical evidence presented in sections 3 and 4 shows that the low frequency variability in SAM pattern-as conventionally defined (based on the leading EOF of SH circulation) - is partly tropically forced. To better understand the underlying dynamics, we calculate the Rossby wave source (RWS), as defined in Sardeshmukh and Hoskins $(1988),-\nabla \cdot\left(\mathbf{v}_{\chi} \cdot \zeta\right)$, where $\zeta$ is the absolute vorticity, and $\mathbf{v}_{\chi}$ is the divergent component of the horizontal velocity field.

In all seasons except summer, the SH upper troposphere exhibits a double (split) jet structure (Fig. 14) with a strong subtropical jet near $30^{\circ} \mathrm{S}$ in the Pacific and an eddy-driven midlatitude jet along $50^{\circ} \mathrm{S}$ over the Indian Ocean (Bals-Elsholz et al. 2001; Nakamura and Shimpo 2004). In summer the subtropical jet in the Pacific is severely weakened and a prominent jet is only present over the Indian Ocean.

In the nonsummer season, the core of the subtropical jet is located to the east of Australia along $30^{\circ} \mathrm{S}$. The tight vorticity gradient associated with the jet and the strong variability of upper-level divergent flow over the warm pool should combine to form an active source of Rossby waves over the jet core region (Renwick and Revell 1999; Lachlan-Cope and Connolley 2006). Indeed, as shown in Fig. 14, the year-to-year variability of the seasonal mean RWS exhibits an active region along the subtropical jet with a maximum to the east of Australia. Thus, the most active RWS in the subtropical SH is confined to a fairly small geographic region. The resulting wave train from this location tends to propagate along a "great circle" path to West Antarctica because the path of an extratropical wave train is largely determined by the properties of the basic state flow. The strong wave flux emanating from subtropical Australia toward West Antarctica that projects upon the SAM pattern (Fig. 2a) is further evidence that the "pole of variability" over the Amundsen Sea (Connnolly 1997) is related to the characteristics of the basic state in the tropics and subtropics.

The most active and spatially extensive subtropical Rossby wave source occurs in JJA when the jet itself is strongest (Fig. 14c). When the subtropical jet along $30^{\circ} \mathrm{S}$ almost disappears in the austral summer, the variability of the RWS is only half as large (Fig. 14a), but this is the time when the SST variability over the tropical Pacific is strongest. Thus, the location and seasonality of RWS activity appears to be mainly determined by the seasonal evolution of the intensity and shape of the jet stream, rather than by the strength of the variability of tropical SST. When the RWS activity over the core of the jet is weakest in DJF, the circulation variability over the 
a) JJA mode $1 \mathrm{SCF}=41 \%$

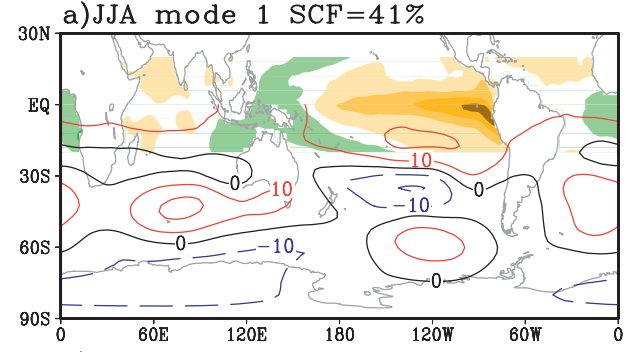

c) Timeseries of JJA mode $1 \mathrm{r}=0.75$

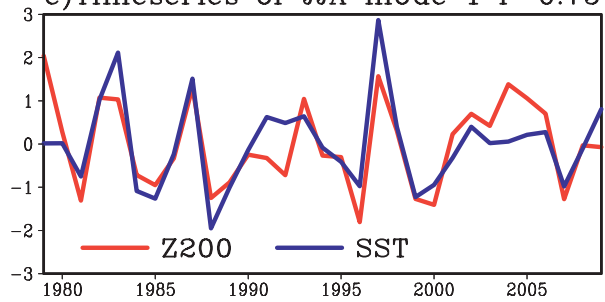

b) JJA mode $2 \mathrm{SCF}=31 \%$
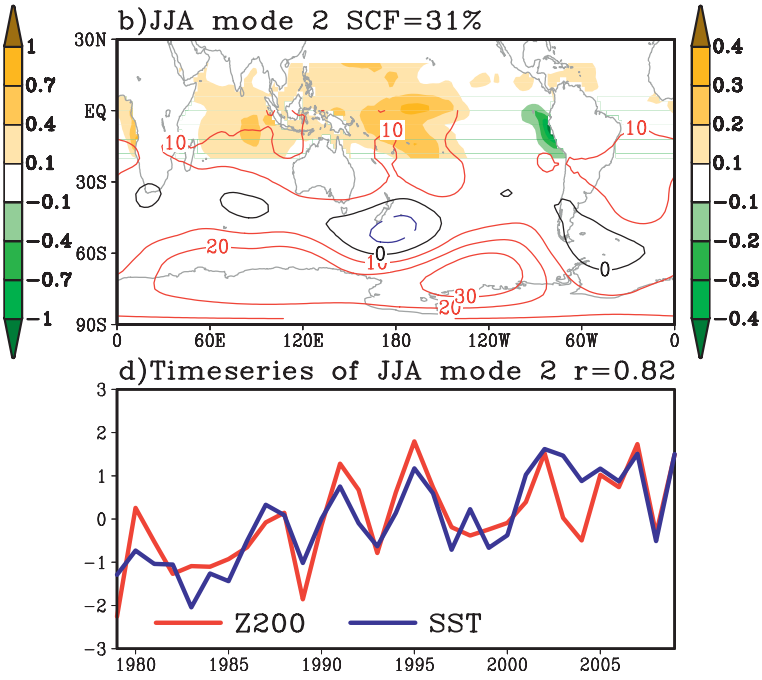

FIG. 13. As in Fig. 12, but for austral winter (JJA). Note that the upward trends in both time series in mode 2 are significant at the $99 \%$ confidence level by the Mann-Kendall test and signal-to-noise ratio test. Figure from Ding et al. (2011) and reproduced with permission from Nature Geoscience.

Amundsen Sea is also relatively weak. This is additional evidence that the interannual variability of the highlatitude SH circulation in the Pacific sector is more directly related to conditions in the tropics than to eddymean flow interactions or high-latitude orographic effects.

Because the circulation response to tropical SST forcing yields a pair of Rossby wave gyres residing to the west and poleward of the forcing, whose divergent wind field has a much larger meridional width and a stronger intensity than that associated with Kelvin waves (Gill 1980), the tropical SST anomalies to the east of Australia are efficient in triggering an active RWS in the core region of the subtropical jet. This is consistent with the correlation analysis in section $3 \mathrm{~b}$, which shows that $Z_{200}$ variations over the Amundsen Sea are more strongly correlated with SST anomalies over the central and eastern Pacific than with SST anomalies over the Indian Ocean and Western Pacific.

Considering the very active RWS along the core of subtropical jet, tropical internal instability largely unrelated to tropical SST anomalies could also excite fluctuations resembling the PSA wave train if it were able to generate a strong wave source over the jet core region. If this were the case, then one would expect the PSA signature to be prominent in the SH circulation variability, not only on interannual time scales but also intraseasonally. To explore this possibility, EOF analysis was performed on pentad-mean $\mathrm{SH} \quad Z_{200}$ anomalies
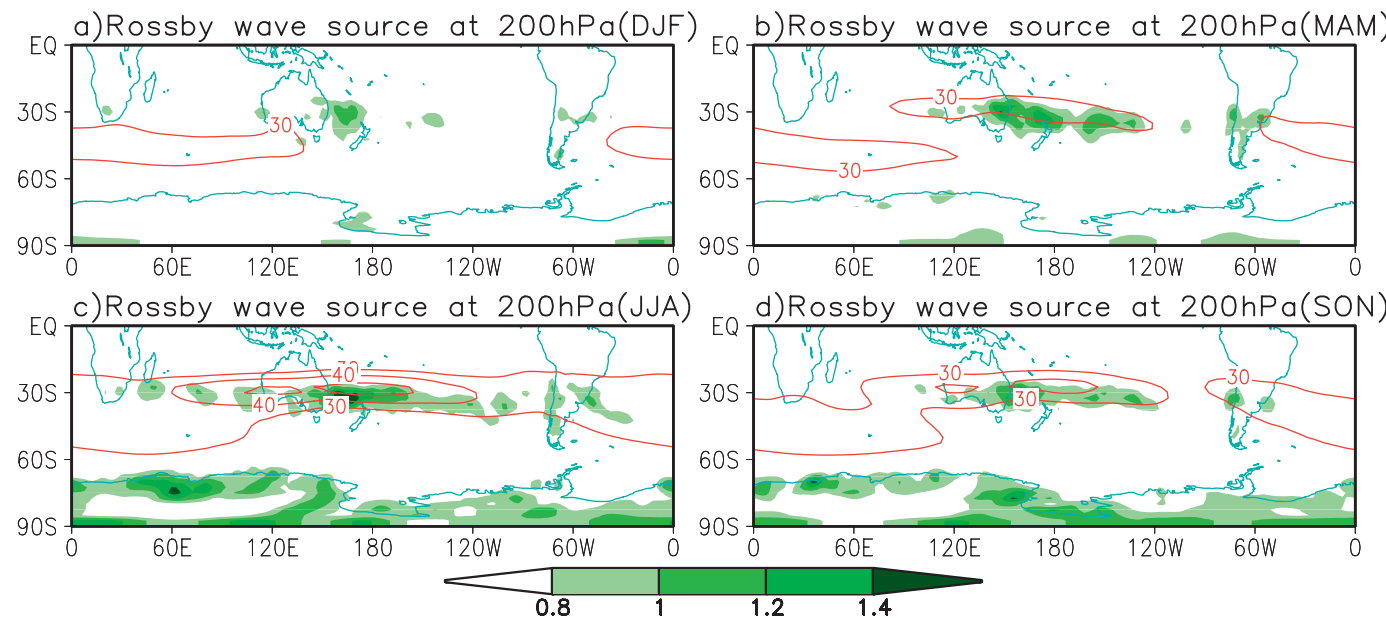

FIG. 14. Standard deviation of 31-yr (1979-2009) seasonal mean Rossby wave source (shading, unit $10^{-10} \mathrm{~s}^{-2}$ ), together with isotachs of climatological seasonal mean 200-hPa zonal wind indicating the location of the jet stream (red contours, $10 \mathrm{~m} \mathrm{~s}^{-1}$ contour interval, values $>30 \mathrm{~m} \mathrm{~s}^{-1}$ only) for (a) DJF, (b) MAM, (c) JJA, and (d) DJF. 


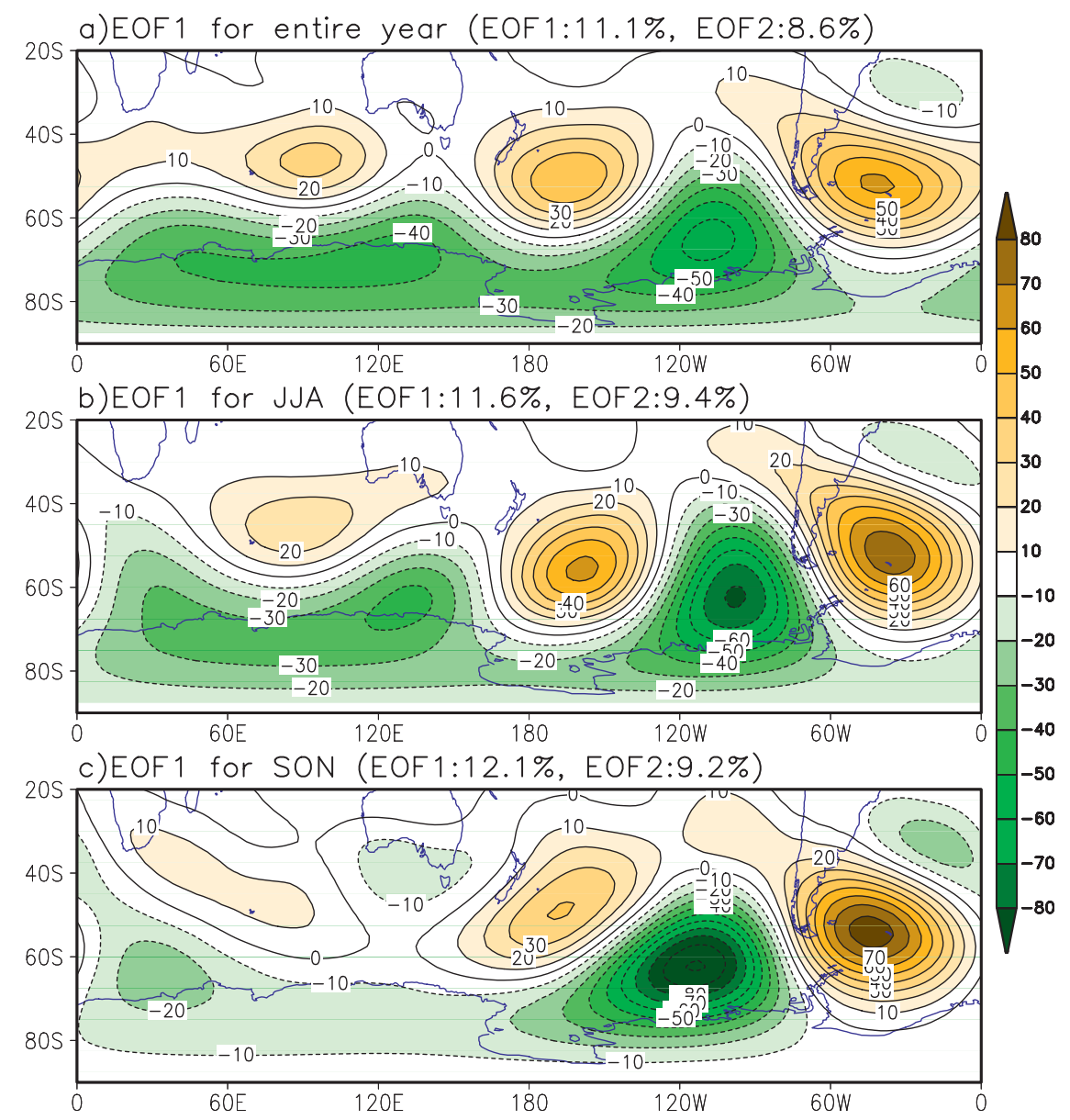

FIG. 15. EOF1 of 31-yr (1979-2009) pentad-mean SH 200-hPa height anomalies (contour interval $10 \mathrm{~m}$ ) for (a) the entire year, (b) JJA only, and (c) SON only. EOF1 has been scaled by one standard deviation of the corresponding principal component. Variance explained by the leading two EOFs is denoted above each panel: the first two EOFs are well separated based on North et al. (1982).

separately for each season and for the year as a whole. In MAM and DJF the leading two EOFs are not statistically separable according to the North et al. (1982) criterion (figures not shown). Possibly meaningful EOF1 patterns that are well separated from the second EOF are observed only in the calculation based on pentad anomalies for JJA, SON, and for the entire year. The leading EOFs for JJA, SON, and for the year, shown in Fig. 15, are very much alike and all bear a strong resemblance to their counterparts derived from monthly or seasonal mean data shown in Fig. 4. The PSA wave train is even more pronounced in the intraseasonal EOF1 than in the interannual EOF1. Because tropical SST fluctuations should be very small on the intraseasonal time scale, this suggests that the PSA-like pattern obtained from pentad data reflects an extratropical response to tropical internal variability rather than a SST-forced response. It thus appears that the PSA pattern is a preferred mode of the extratropical basic state that is very sensitive to small variations in the tropical convection: tropical SST forcing is one way to force such variations, but it is not a requirement. This explains why the SAM strongly projects on the PSA pattern over a broad range of frequencies.

In Fig. 16 we present a schematic diagram that highlights the complementary roles of the subtropical jet in the south Pacific and the midlatitude jet in the Indian Ocean in shaping the SAM during the seasons when the basic state is characterized by a double jet structure (i.e., in all seasons other than summer). Circulation variability associated with a meridional shift of the eddy-driven midlatitude jet favors eddy feedback that tends to sustain a meridional seasaw mode between the Indian Ocean and East Antarctica (Barnes and Hartmann 2010). The subtropical jet driven by the Hadley circulation inhibits eddy feedback (Eichelberger and Hartmann 2007) but favors the generation of a Rossby wave source over its core region on a broad frequency band. Thus, a Rossby wave train emanating from subtropical Australia to West 


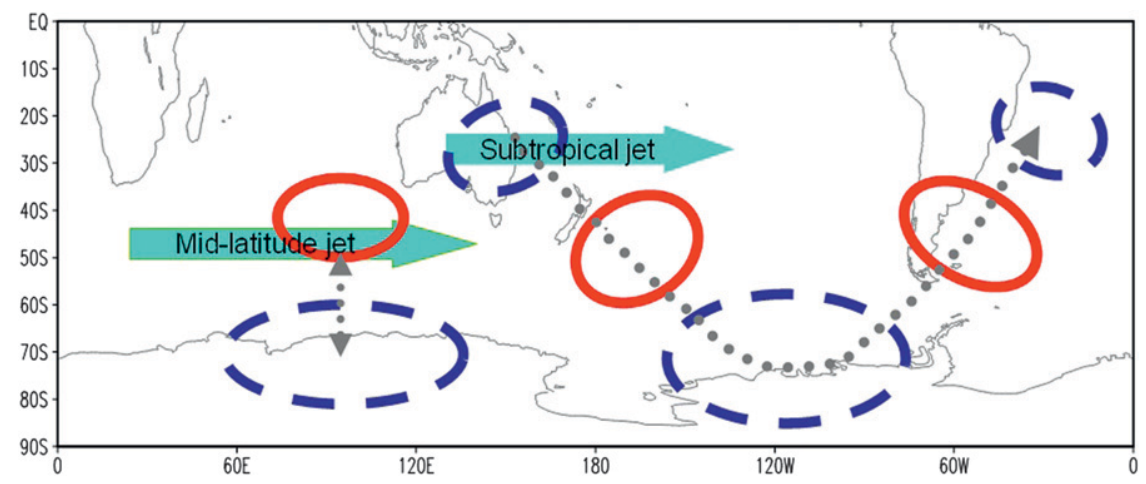

FIG. 16. Schematic showing the role of subtropical jet and midlatitude jet in shaping the SAM during nonsummer season when the basic state is characterized by the double jet structure. See discussion section for further details.

Antarctica is the preferred circulation mode of the basic state in the Pacific sector. In all seasons but summer, two different leading oscillation modes in the India Ocean and Pacific sector work together to establish the annular SAM pattern that exhibits strong zonal mean structure and out of phase action between the midlatitude and the high latitude. In austral summer, the basic state of the $\mathrm{SH}$ is dominated by a single jet structure in the midlatitude. The eddy feedback is thus the main dynamical source to maintain an annular SAM in that season (Lorenz and Hartmann 2001). This is also the season when ENSO tends to reach its peak. The extratropical response to a mature ENSO also exhibits a PSA type wave train but with stronger meridional orientation and zonal mean structure, which may further strengthen the variability of the annular character of SAM in austral summer (Seager et al. 2003; L'Heureux and Thompson 2006).

\section{b. Dynamics of the SAM trend}

The summer (DJF) trend in the SAM over the past 30 years has been most commonly attributed to the direct influence of radiative forcing from both greenhouse gases and ozone depletion (Thompson and Solomon 2002; Gillett and Thompson 2003; Marshall et al. 2004; Shindell and Schmidt 2004; Arblaster and Meehl 2006; Miller et al. 2006), but the winter trend, which is of the opposite sign, cannot be readily explained by the same forcing. The longterm change of JJA SST in the tropics, as revealed by MCA, is an obvious candidate. The abrupt rise in the summertime SAM index in the mid-1990s may have also been at least partly due to the abrupt change of DJF SST in the tropical Pacific, which occurred around the same time.

Ding et al. (2011) used a general circulation model to show that the JJA SST warming trend in the tropical central Pacific/SPCZ region generates a PSA-shaped trend in the SH circulation. Given the strong projection of the Pacific-South American pattern upon the SAM, we suggest that the forcing attributable to SST warming in the tropical central Pacific explains a substantial part of the observed trend in the SAM in winter. Similarly, the DJF SST warming over most of the tropics along with cooling in the eastern Pacific also has the potential to excite a zonally symmetric response in the extratropics by changing the Hadley cell and the midlatitude jet stream (Seager et al. 2003; L'Heureux and Thompson 2006; Grassi et al. 2005), suggesting a further possible contribution of tropical SST to the SAM summer trend.

\section{Summary and conclusions}

The focus of this study is to examine the relationship between the southern annular mode and SST variability in the tropics. Analyses based on EOF1 of monthly geopotential height at $200 \mathrm{hPa}$ show that the SAM pattern contains strong zonally asymmetric variability and that in the Pacific sector it projects strongly upon the PSA wave train that is mainly forced by SST anomalies in the equatorial central-eastern Pacific. It follows that the SAM variability is related to tropical Pacific SST variability, as confirmed by the significant correlation of the SAM index with tropical central Pacific SST in JJA and tropical central and eastern Pacific SST in DJF.

The PSA pattern arises from a Rossby wave source in the upper troposphere to the east of Australia along $30^{\circ} \mathrm{S}$, which is active throughout the year. The intensity of this Rossby wave source is mainly determined by the strength and sharpness of the subtropical jet in the basic state flow. This geographically fixed wave source may play an important role in anchoring the PSA wave train and favoring the recurrence of the PSA, with its primary center of action off the West Antarctic coast, even in the absence of a spatially coherent pattern of SST variability over the central Pacific.

When circulation variability associated with the PSA in the $\mathrm{SH}$ circulation is regressed out of the hemispheric 
200-hPa height field, the leading EOF exhibits a zonal dipole structure confined to the Indian Ocean sector, suggesting that the behavior of the SAM over the Indian Ocean sector and Pacific sector is different. In combination, these results indicate that the SAM, which has conventionally been regarded as the leading EOF mode of SH circulation variability, in fact represents the superposition of a PSA type wave train in the Pacific sector and a meridional dipole pattern in the Indian Ocean sector. Although eddy-mean flow interaction in the extratropics is widely believed to be the primary source of SAM variability, our study shows that planetary waves emanating from the tropical Pacific also strongly contribute to the variability of the SAM.

The long-term trend in the SAM over the past three decades is also examined with emphasis on its connection with tropical SST. The SAM trend in summer is well known and has already been extensively discussed in previous work. The SAM index also exhibits a detectable downward trend in winter and the associated uppertropospheric geopotential height pattern in the Pacific sector projects strongly onto the PSA wave train. The interdecadal changes in the SAM in winter and summer are of opposing sign, and their time history is different. The summer SAM index exhibited an abrupt shift in the mid-1990s, whereas the main shift in the winter SAM began a decade earlier and was more gradual. In both winter and summer, a close association is observed between the change in the SAM index and tropical SST changes. In JJA central Pacific SST experienced a marked warming from the 1980s to the 1990s, accompanied by a downward trend in the SAM index, while in DJF eastern Pacific SST exhibited a marked cooling around the middle of the 1990s, coincident with a rise in the SAM index.

Acknowledgments. This work was supported by the US National Science Foundation, Grants OPP-0837988 and 0963924 to EJS and AGS-1122989 to JWM.

\section{APPENDIX A}

\section{Plumb (1985) Wave Activity Analysis}

The Plumb (1985) wave activity analysis is used to reveal stationary Rossby wave energy propagation. In spherical coordinates,

Plumb flux $=\frac{p \cos \varphi}{p_{0}}\left[\begin{array}{l}v^{\prime 2}-\frac{1}{2 \Omega a \sin 2 \varphi} \frac{\partial\left(v^{\prime} \Phi^{\prime}\right)}{\partial \lambda} \\ -u^{\prime} v^{\prime}+\frac{1}{2 \Omega a \sin 2 \varphi} \frac{\partial\left(u^{\prime} \Phi^{\prime}\right)}{\partial \lambda}\end{array}\right]$, where $(\varphi, \lambda)$ are the coordinates (latitude, longitude); $p$ is pressure; $p_{0}=1000 \mathrm{mb} ; u^{\prime}, v^{\prime}$, and $\Phi^{\prime}$ are the stationary disturbance's zonal wind, meridional wind, and geopotential height, respectively; and $a$ and $\Omega$ are the earth's radius and rotation rate, respectively. The Plumb flux provides direct information on the flux of wave activity, which is parallel to the group velocity of quasi-stationary Rossby waves. This diagnostic tool is well suited for detection of propagation characteristics of large scale quasistationary Rossby waves.

\section{APPENDIX B}

\section{Number of Degrees of Freedom}

For the correlation of monthly data in Fig. 2c, the effective sample size $N^{*}$ is computed by considering the lag-1 autocorrelations of the SAM index $\left(r_{1}=0.4\right)$ and tropical SST $\left(1.0>r_{2}>0.9\right.$ in most of tropical grids) following Bretherton et al. (1999):

$$
N^{*}=N \frac{1-r_{1} r_{2}}{1+r_{1} r_{2}}
$$

where $N$ is the number of available time steps and $r_{1}$ and $r_{2}$ are the lag-1 autocorrelation of monthly SAM index and tropical SST. The corrected sample size for the 372month (31 years) time series is about 160 .

\section{APPENDIX C}

\section{MCA Analysis}

We use maximum covariance analysis (MCA) to capture the dominant coupled modes between Southern Hemisphere $Z_{200}$ (equator to $87.5^{\circ} \mathrm{S}$ ) and tropical SST $\left(20^{\circ} \mathrm{N}\right.$ to $\left.20^{\circ} \mathrm{S}\right)$. MCA between the $Z_{200}$ and SST field is achieved by performing singular value decomposition on the temporal covariance matrix (Bretherton et al. 1992; Wallace et al. 1992), using equal area [square root of $\cos ($ lat)] weighting. The pairs of singular vectors describe the spatial patterns of the respective fields. The corresponding squared singular value divided by the sum of the squares of the singular values represents the squared covariance fraction (SCF) and thus indicates the relative importance of that pair of vectors in relationship to the total squared covariance between the two fields. The expansion coefficients obtained by projecting the singular vectors onto the original data fields depict the temporal variations in amplitude and polarity of the spatial patterns. 


\section{REFERENCES}

Arblaster, J. M., and G. A. Meehl, 2006: Contributions of external forcings to southern annular mode trends. J. Climate, 19, 28962905.

Bals-Elsholz, T. M., E. H. Atallah, L. F. Bosart, T. A. Wasula, M. J. Cempa, and A. R. Lupo, 2001: The wintertime Southern Hemisphere split jet: Structure variability and evolution. J. Climate, 14, 4191-4215.

Barnes, E. A., and D. L. Hartmann, 2010: Dynamical feedbacks of the southern annular mode in winter and summer. J. Atmos. Sci., 67, 2320-2330.

Blunden, J., D. S. Arndt, and M. O. Baringer, Eds., 2011: State of the climate in 2010. Bull. Amer. Meteor. Soc., 92, S1-S266.

Bretherton, C. S., C. Smith, and J. M. Wallace, 1992: An intercomparison of methods for finding coupled patterns in climate data. J. Climate, 5, 541-560.

_ , M. Widmann, V. P. Dymnidov, J. M. Wallace, and I. Blade, 1999: The effective number of spatial degrees of freedom of a time-varying field. J. Climate, 12, 1990-2009.

Butler, A. H., D. W. J. Thompson, and K. R. Gurney, 2007: Observed relationships between the southern annular mode and atmospheric carbon dioxide. Global Biogeochem. Cycles, 21, GB4014, doi:10.1029/2006GB002796.

Cash, B. A., P. J. Kushner, and G. K. Vallis, 2002: The structure and composition of the annular modes in an aquaplanet general circulation model. J. Atmos. Sci., 59, 3399-3414.

Ciasto, L. M., and D. W. J. Thompson, 2008: Observations of largescale ocean-atmosphere interaction in the Southern Hemisphere. J. Climate, 21, 1244-1259.

Codron, F., 2005: Relation between annular modes and the mean state: Southern Hemisphere summer. J. Climate, 18, 320-330.

Cohen, J., and K. Saito, 2002: A test for annular modes. J. Climate, 15, 2537-2546.

Connolley, W. M., 1997: Variability in annual mean circulation in southern high latitudes. Climate Dyn., 13, 745-756.

DeWeaver, E., and S. Nigam, 2000: Zonal-eddy dynamics of the North Atlantic Oscillation. J. Climate, 13, 3893-3914.

Ding, Q., E. J. Steig, D. S. Battisti, and M. Küttel, 2011: Winter warming in West Antarctica caused by central tropical Pacific warming. Nat. Geosci., 4, 398-403, doi:10.1038/ngeo1129.

Eichelberger, S. J., and D. L. Hartmann, 2007: Zonal jet structure and the leading mode of variability. J. Climate, 20, 5149-5163.

Feldstein, S., and S. Lee, 1998: Is the atmospheric zonal index driven by an eddy feedback? J. Atmos. Sci., 55, 3077-3086.

Fogt, R., and D. Bromwich, 2006: Decadal variability of the ENSO teleconnection to the high-latitude South Pacific governed by coupling with the southern annular mode. J. Climate, 19,979-997.

Gerber, E. P., and G. Vallis, 2005: A stochastic model for the spatial structure of annular patterns of variability and the North Atlantic Oscillation. J. Climate, 18, 2102-2118.

Gill, A. E., 1980: Some simple solutions for heat-induced tropical circulation. Quart. J. Roy. Meteor. Soc., 106, 447-462.

Gillett, N. P., and D. W. J. Thompson, 2003: Simulation of recent Southern Hemisphere climate change. Science, 302, 273-275.

— T. D. Kell, and P. D. Jones, 2006: Regional climate impacts of the southern annular mode. Geophys. Res. Lett., 33, L23704, doi:10.1029/2006GL027721.

Gong, D. Y., and S. W. Wang, 1999: Definition of Antarctic Oscillation index. Geophys. Res. Lett., 26, 459-462.

Grassi, B., G. Redaelli, and G. Visconti, 2005: Simulation of Polar Antarctic trends: Influence of tropical SST. Geophys. Res. Lett., 32, L23806, doi:10.1029/2005GL023804.
Hall, A., and M. Visbeck, 2002: Synchronous variability in the Southern Hemisphere atmosphere, sea ice, and ocean resulting from the annular mode. J. Climate, 15, 3043-3057.

Hartmann, D. L., and F. Lo, 1998: Wave-driven zonal flow vacillation in the Southern Hemisphere. J. Atmos. Sci., 55, 13031315.

Hendon, H. H., D. W. J. Thompson, and M. C. Wheeler, 2007: Australian rainfall and surface temperature variations associated with the Southern Hemisphere annular mode. J. Climate, 20, 2452-2467.

Hoskins, B. J., and D. J. Karoly, 1981: The steady linear response of a spherical atmosphere to thermal and orographic forcing. J. Atmos. Sci., 38, 1179-1196.

Kanamitsu, M., W. Ebisuzaki, J. Woollen, S. K. Yang, J. J. Sling, M. Fiorino, and G. L. Potter, 2002: NCEP-DOE AMIP-II Reanalysis (R-2). Bull. Amer. Meteor. Soc., 83, 1631-1643.

Karoly, D. J., 1989: Southern Hemisphere circulation features associated with El Niño Southern-Oscillation events. J. Climate, 2, 1239-1252.

, 1990: The role of transient eddies in low-frequency zonal variations of the Southern Hemisphere circulation. Tellus, 42A, 41-50.

Kendall, M. G., 1955: Rank Correlation Methods. 2nd ed. Charles Griffin, 196 pp.

Kidson, J. W., 1988: Indices of the Southern Hemisphere zonal wind. J. Climate, 1, 183-194.

_ 1999: Principal modes of Southern Hemisphere low-frequency variability obtained from NCEP-NCAR reanalyses. J. Climate, 12, 2808-2830.

_ and M. R. Sinclair, 1995: The influence of persistent anomalies on Southern Hemisphere storm tracks. J. Climate, 8, 1938-1950

Kidston, J., J. A. Renwick, and J. McGregor, 2009: Hemisphericscale seasonality of the southern annular mode and impacts on the climate of New Zealand. J. Climate, 22, 4759-4770.

Kim, W., S. W. Yeh, J. H. Kim, J. S. Kug, and M. Kwon, 2011: The unique 2009-2010 El Niño event: A fast phase transition of warm pool El Niño to La Niña. Geophys. Res. Lett., 38, L15809, doi:10.1029/2011GL048521.

Kushner, P. J., and G. Lee, 2007: Resolving the regional signature of the annular modes. J. Climate, 20, 2840-2852.

Lachlan-Cope, T., and W. Connolley, 2006: Teleconnections between the tropical Pacific and the Amundsen-Bellinghausens Sea: Role of the El Niño/Southern Oscillation. J. Geophys. Res., 111, D23101, doi:10.1029/2005JD006386.

Lachlan-Cope, T. A., W. M. Connolley, and J. Turner, 2001: The role of the nonaxisymmetric Antarctic orography in forcing the observed pattern of variability of the Antarctic climate. Geophys. Res. Lett., 28, 4111-4114.

Lefebvre, W., H. Goosse, R. Timmermann, and T. Fichefet, 2004: Influence of the southern annular mode on the sea ice-ocean system. J. Geophys. Res., 109, C09005, doi:10.1029/2004JC002403.

L'Heureux, M. L., and D. W. J. Thompson, 2006: Observed relationships between the El Niño-Southern Oscillation and the extratropical zonal-mean circulation. J. Climate, 19, 276-287.

Liebmann, B., and C. A. Smith, 1996: Description of a complete (interpolated) OLR dataset. Bull. Amer. Meteor. Soc., 77, 1275-1277.

Limpasuvan, V., and D. L. Hartmann, 2000: Wave-maintained annular modes of climate variability. J. Climate, 13, 44144429.

Lorenz, D. J., and D. L. Hartmann, 2001: Eddy-zonal flow feedback in the Southern Hemisphere. J. Atmos. Sci., 58, 3312-3327. 
Lovenduski, N. S., and N. Gruber, 2005: Impact of the southern annular mode on Southern Ocean circulation and biology. Geophys. Res. Lett., 32, L11603, doi:10.1029/2005GL022727.

,-- S. C. Doney, and I. D. Lima, 2007: Enhanced $\mathrm{CO}_{2}$ outgassing in the Southern Ocean from a positive phase of the southern annular mode. Global Biogeochem. Cycles, 21, GB2026, doi:10.1029/2006GB002900.

Marshall, G. J., 2003: Trends in the southern annular mode from observations and reanalyses. J. Climate, 16, 4134-4143.

— P. A. Stott, J. Turner, W. M. Connolley, J. C. King, and T. A. Lachlan-Cope, 2004: Causes of exceptional atmospheric circulation changes in the Southern Hemisphere. Geophys. Res. Lett., 31, L14205, doi:10.1029/2004GL019952.

Miller, R. L., G. A. Schmidt, and D. T. Shindell, 2006: Forced annular variations in the 20th century Intergovernmental Panel on Climate Change Fourth Assessment Report models. J. Geophys. Res., 111, D18101, doi:10.1029/2005JD006323.

Mo, K. C., 2000: Relationships between low-frequency variability in the Southern Hemisphere and sea surface temperature anomalies. J. Climate, 13, 3599-3610.

Nakamura, H., and A. Shimpo, 2004: Seasonal variations in the Southern Hemisphere storm tracks and jet streams as revealed in a reanalysis dataset. J. Climate, 17, 1828-1844.

North, G. R., T. L. Bell, R. F. Cahalan, and F. J. Moeng, 1982: Sampling errors in the estimation of empirical orthogonal functions. Mon. Wea. Rev., 110, 699-706.

Plumb, R. A., 1985: On the three-dimensional propagation of stationary waves. J. Atmos. Sci., 42, 217-229.

Rashid, H. A., and I. Simmonds, 2004: Eddy-zonal flow interactions associated with the Southern Hemisphere annular mode: Results from NCEP-DOE reanalysis and a quasi-linear model. J. Atmos. Sci., 61, 873-888.

Renwick, J. A., and M. J. Revell, 1999: Blocking over the South Pacific and Rossby wave propagation. Mon. Wea. Rev., 127, 2233-2247.

Robinson, W. A., 1991: The dynamics of the zonal index in a simple model of the atmosphere. Tellus, 43A, 295-305.

Sallée, J.-B., K. Speer, and S. Rintoul, 2010: Zonally asymmetric response of the Southern Ocean mixed-layer depth to the Southern Annular Mode. Nat. Geosci., 3, 273-279.

Sardeshmukh, P. D., and B. J. Hoskins, 1988: The generation of global rotational flow by steady idealized tropical divergence. J. Atmos. Sci., 45, 1228-1251.

Screen, J., N. Gillett, D. Stevens, G. Marshall, and H. Roscoe, 2009: The role of eddies in the Southern Ocean temperature response to the southern annular mode. J. Climate, 22, 806-818.

Seager, R., N. Harnik, Y. Kushnir, W. Robinson, and J. Miller, 2003: Mechanisms of hemispherically symmetric climate variability. J. Climate, 16, 2960-2978.

Sen Gupta, A. S., and M. H. England, 2006: Coupled oceanatmosphere-ice response to variations in the southern annular mode. J. Climate, 19, 4457-4486.
— and _ 2007: Coupled ocean-atmosphere feedback in the southern annular mode. J. Climate, 20, 3677-3692.

Shindell, D. T., and G. A. Schmidt, 2004: Southern Hemisphere climate response to ozone changes and greenhouse gas increases. Geophys. Res. Lett., 31, L18209, doi:10.1029/2004GL 020724.

Shiotani, M., 1990: Low-frequency variations of the zonal mean state of the Southern Hemisphere troposphere. J. Meteor. Soc. Japan, 68, 461-470.

Silvestri, G. E., and C. S. Vera, 2003: Antarctic Oscillation signal on precipitation anomalies over southeastern South America. Geophys. Res. Lett., 30, 2115, doi:10.1029/2003GL018277.

Smith, T. M., R. W. Reynolds, T. C. Peterson, and J. Lawrimore, 2008: Improvements to NOAA's historical merged landocean surface temperature analysis (1880-2006). J. Climate, 21, 2283-2296.

Stammerjohn, S. E., D. G. Martinson, R. C. Smith, X. Yuan, and D. Rind, 2008: Trends in Antarctic annual sea ice retreat and advance in relation to El Niño-Southern Oscillation and southern annular mode variability. J. Geophys. Res., 113, C03S90, doi:10.1029/2007JC004269.

Thompson, D. W. J., and J. M. Wallace, 2000: Annular modes in the extratropical circulation. Part I: Month-to-month variability. J. Climate, 13, 1000-1016.

— , and S. Solomon, 2002: Interpretation of recent Southern Hemisphere climate change. Science, 296, 895-899.

_ M. P. Baldwin, and S. Solomon, 2005: Stratosphere-troposphere coupling in the Southern Hemisphere. J. Atmos. Sci., 62, 708-715.

Trenberth, K. E., G. W. Branstator, D. Karoly, A. Kumar, N. C. Lau, and C. Ropelewski, 1998: Progress during TOGA in understanding and modeling global teleconnections associated with tropical sea surface temperatures. J. Geophys. Res., 103 (C7), 14 291-14 324.

Uppala, S. M., and Coauthors, 2005: The ERA-40 Re-Analysis. Quart. J. Roy. Meteor. Soc., 131, 2961-3012.

Vallis, G. K., E. P. Gerber, P. J. Kushner, and B. A. Cash, 2004: A mechanism and simple dynamical model of the North Atlantic Oscillation and annular modes. J. Atmos. Sci., 61, 264-280.

Van den Dool, H. M., S. Saha, and A. Johansson, 2000: Empirical orthogonal teleconnections. J. Climate, 13, 1421-1435.

Van Loon, H., and R. L. Jenne, 1972: The zonal harmonic standing waves in the Southern Hemisphere. J. Geophys. Res., 77, $992-$ 1003.

Wallace, J. M., C. Smith, and C. S. Bretherton, 1992: Singular value decomposition of wintertime sea surface temperature and 500-mb height anomalies. J. Climate, 5, 561-576.

Watterson, I. G., 2001: Zonal wind vacillation and its interaction with the ocean: Implication for interannual variability and predictability. J. Geophys. Res., 106 (D20), 965-975.

Wilks, D. S., 1995: Statistical Methods in the Atmospheric Sciences: An Introduction. Academic Press, 467 pp. 